\title{
A systematic assessment of chemical, genetic, and epigenetic factors influencing the activity of anticancer drug KP1019 (FFC14A)
}

\author{
Upendarrao Golla ${ }^{1}$, Swati Swagatika ${ }^{1}$, Sakshi Chauhan ${ }^{1}$ and Raghuvir Singh Tomar ${ }^{1}$ \\ ${ }^{1}$ Laboratory of Chromatin Biology, Department of Biological Sciences, Indian Institute of Science Education and Research \\ (IISER), Bhopal 462066, India
}

Correspondence to: Raghuvir Singh Tomar, email: rst@iiserb.ac.in

Keywords: anticancer; KP1019; histones; transcriptomics; metal homeostasis

Received: April 27, $2017 \quad$ Accepted: August 28, $2017 \quad$ Published: September 30, 2017

Copyright: Golla et al. This is an open-access article distributed under the terms of the Creative Commons Attribution License 3.0 (CC BY 3.0), which permits unrestricted use, distribution, and reproduction in any medium, provided the original author and source are credited.

\section{ABSTRACT}

KP1019 ([trans-RuCl$\left.{ }_{4}(1 \mathrm{H} \text {-indazole) })_{2}\right] ; \mathrm{FFC14A}$ ) is one of the promising ruthenium-based anticancer drugs undergoing clinical trials. Despite the pre-clinical and clinical success of KP1019, the mode of action and various factors capable of modulating its effects are largely unknown. Here, we used transcriptomics and genetic screening approaches in budding yeast model and deciphered various genetic targets and plethora of cellular pathways including cellular signaling, metal homeostasis, vacuolar transport, and lipid homeostasis that are primarily targeted by KP1019. We also demonstrated that KP1019 modulates the effects of TOR (target of rapamycin) signaling pathway and induces accumulation of neutral lipids (lipid droplets) in both yeast and HeLa cells. Interestingly, KP1019-mediated effects were found augmented with metal ions $\left(\mathrm{Al}^{3+} / \mathrm{Ca}^{2+} / \mathrm{Cd}^{2+} / \mathrm{Cu}^{2+} / \mathrm{Mn}^{2+} / \mathrm{Na}^{+} / \mathrm{Zn}^{2+}\right)$, and neutralized by $\mathrm{Fe}^{2+}$, antioxidants, osmotic stabilizer, and ethanolamine. Additionally, our comprehensive screening of yeast histone $\mathrm{H3} / \mathrm{H} 4$ mutant library revealed several histone residues that could significantly modulate the KP1019-induced toxicity. Altogether, our findings in both the yeast and HeLa cells provide molecular insights into mechanisms of action of KP1019 and various factors (chemical/genetic/epigenetic) that can alter the therapeutic efficiency of this clinically important anticancer drug.

\section{INTRODUCTION}

Cancer is an extremely diverse disease characterized by uncontrolled proliferation of abnormal cells that expands into surrounding tissues. The major factors for oncogenic transformation and cancer development include not only genetic changes in the proto-oncogenes, tumor suppressor genes, and DNA repair genes $[1,2]$, but also the aberrant pattern in epigenetic mechanisms such as DNA methylation and histone modifications [3, 4]. In addition, errors in cell division, DNA damage, substantial exposure to environmental toxic chemicals, and radiation can cause cancer. Although there are more than 200 anticancer drugs listed by the National Cancer Institute in the USA (http://www.cancer.gov/cancertopics/ alphalist), combating cancer is troublesome due to their distinctive genetic and phenotypic heterogeneity, failure in early detection, inefficient chemotherapy treatment and its associated severe adverse effects, and development of drug-resistance. The failure to decipher and target the multiple underlying pathways of molecular carcinogenesis is a major challenge for anticancer drug development. Hence, recent efforts are being made towards developing additional therapeutic molecules targeting the plethora of cancer mechanisms to achieve higher therapeutic efficiency (specific to cancer cells) with lesser or no adverse effects [5].

The clinical success of platinum-based drugs (cisplatin, oxaliplatin, carboplatin) as potential candidates for the treatment of several cancers has highlighted the 
importance of metal-based therapeutics in medicine. Over the past decade, ruthenium-based complexes have emerged as leading candidates for the next-generation anticancer therapeutics, and many are in the pipeline. The Keppler group has developed many ruthenium (III) based co-ordination complexes, of which KP1019 (indazolium $\left[\right.$ trans- $\left.\left.\mathrm{RuCl}_{4}(1 \mathrm{H} \text {-indazole })_{2}\right]\right)$ has demonstrated most promising anticancer activity with minimal side-effects in the undergoing clinical trials [6]. During pre-clinical development, KP1019 has shown activity against a wide variety of cancer cell lines, advanced and metastatic solid malignancies, without dose-limiting toxicity [7]. Strikingly, Heffeter et al. reported that KP1019 activity is not hampered by conventional mechanisms of intrinsic drug resistance and it has very less probability of acquiring insensitivity during therapy. Accordingly, KP1019 was found effective against cancer cell lines that were resistant to other anticancer drugs such as doxorubicin, thus emerging as a promising anticancer drug of choice for the treatment of drug-resistant tumors [8].

In addition to its anticancer property, KP1019 was found effective against $\beta$-amyloid aggregate induced neurotoxicity in vitro, thus might be used for the treatment of Alzheimer's disease, a neurodegenerative disorder [9]. Considering the therapeutic potential of KP1019, its sodium salt KP1339 (sodium $\left[\right.$ trans $\left.-\mathrm{RuCl}_{4}(1 \text { Hindazole) })_{2}\right]$ ) was developed to improve its solubility. It has shown promising results in phase-I trials against a variety of solid tumors [10], non-small cell lung cancer, sarcoma and colorectal cancers [11]. Several other efforts have been made to improve KP1019 stability, solubility and cytotoxic activity by changing the functional groups to Osmium [12], developing the CF3 derivatives [13], using lipiodolbased emulsions [14], polymer-based micelles [15], and biodegradable poly-(lactic acid) based nanoparticles [16].

The multiple oxidation states, hydrolysis behavior, and slow ligand exchange rates of ruthenium makes KP1019 a promising candidate for anticancer drug development. $\mathrm{Ru}$ (III) complexes including KP1019 coordinate with serum proteins (albumin, and transferrin) through their accessible histidine residues [17] and are believed to be then specifically transported to the solid tumor and retained there for longer hours [18]. Later, it was dissected that the cellular uptake of KP1019 occurs by both transferrin-dependent and transferrinindependent mechanisms [19]. Additionally, KP1019 is widely believed to be a 'prodrug' that gets activated by 'reduction' to highly reactive $\mathrm{Ru}$ (II) selectively in the hypoxic environment of cancer cells [6]. However, recent findings in contrast to the redox activation hypothesis, showed that ruthenium was present in its +III oxidation state $\left(\mathrm{Ru}^{3+}\right)$ after treatment with ruthenium complexes (KP1019 and KP1339) in yeast cells [20] and tissues (tumor/liver/kidney) of a mouse bearing tumors of SW480 colon cancer cells [21]. However, the redox potential of ruthenium was found to be reduced in the presence of biologically relevant reductants (ascorbic acid, glutathione) and thereby modulating the activity of KP1019 under physiological conditions [1, 22, 23]. Since the proposed mechanisms including 'transferrin-mediated uptake' and 'redox activation' for selective accumulation of KP1019 in tumors remain highly debatable, there is a need for further clarifications on the oxidation state and speciation pattern of these ruthenium compounds in cellular environments.

In addition to its strong affinity for plasma proteins, cell fractionation analysis upon KP1019 treatment evidenced strong distribution of ruthenium to nuclei, which is rich in DNA, histone proteins, and chromatin regulators [19, 20]. Subsequently, KP1019 has been shown to bind with histone H3 [24], DNA-modeling nucleotides [22], DNA [25], and is capable of creating inter-strand crosslinks, resolution of which can produce double strand breaks [25]. Further evidence suggests that KP1019 increases the rate of recombination and mutations in yeast, activates DNA damage response wherein DNA repair occurs via mismatch repair, base excision repair, translesion synthesis (TLS), and recombination [26]. In addition, a recent study indicates that KP1019 treatment causes DNA-dependent cell cycle arrest in pre-anaphase, and leads to accumulation of large-budded yeast cells with abnormal nuclear position (spans bud neck) [27]. In our early attempts, we have shown that KP1019 causes osmotic stress, leading to the activation of Hog1 (p38) MAP kinase in yeast [28]. We have also demonstrated that KP1019 can interact specifically with histone H3, and evict histones from the nucleosome in vitro, and is found to be more effective in the absence of chromatin/histone modifying enzymes [24].

Despite the success of KP1019 and current wealth of information largely available on its chemical characterization in vitro, the genetic targets, various cellular pathways and epigenetic events selectively targeted to mediate its anticancer activity in vivo are mostly unknown. The present study is thus aimed to decipher the molecular mechanisms, genetic targets and critical residues of conserved histone $\mathrm{H} 3 / \mathrm{H} 4$ that are required to mediate KP1019-induced cytotoxicity through genome-wide transcriptomics, chemical-genetics approach, and functional screening of synthetic yeast histone H3/H4 mutant library, respectively. Interestingly, comprehensive analysis of our results indicated that KP1019 alters metal ion homeostasis, lipid homeostasis, and can modulate the target of rapamycin (TOR) pathway in addition to its already characterized effects on cell cycle and DNA damage. Furthermore, we report for the first time that cytotoxic potential of KP1019 can be modulated (enhanced/repressed) in the presence of various metal ions, reductants, ethanolamine (ETA) and also by substitution mutations on the histone $\mathrm{H} 3 / \mathrm{H} 4$ residues in vivo. Here, we majorly employed budding yeast, a robust model organism which has been implicated in biomedical research over the 
years to decipher the conserved genetic targets and mode of action of bioactive molecules including anticancer drugs, pollutants and toxicants [29, 30]. Interestingly, we could mimic some of the findings obtained with yeast in human cervical cancer cells (HeLa) that correlate well with the selective cytotoxicity of KP1019, and perhaps also its sodium salt, KP1339 in tumor cells.

\section{RESULTS}

\section{Functional enrichment analysis of KP1019 transcriptome}

KP1019 (Figure 1A) is a lead ruthenium-based anticancer molecule undergoing phase-II clinical trials [31]. In line with earlier reports, KP1019 exhibited dosedependent cytotoxicity as indicated by the decreased growth of wild-type yeast cells (Supplementary Figure 1). To understand the effects of KP1019 on different cellular processes, we performed global transcriptome analysis of wild-type yeast cells treated with a sublethal dose $(50 \mu \mathrm{g} /$ $\mathrm{ml}$ ) of KP1019 for 3h. Interestingly, KP1019 treated yeast cells showed significant upregulation of 284 genes and downregulation of 76 genes $(p \leq 0.05$; fold change $\geq 1.5)$ (Figure 1B, Supplementary Table 2). To investigate the cellular processes targeted by KP1019, the differentially expressed genes (DEG's) were classified according to MIPS (Munich Information Center for Protein Sequences) functional categories [32]. We found that the processes related to energy, metabolism, protein synthesis, proteins with binding function, subcellular localization, cell rescue and defense were enriched significantly in KP1019 transcriptome (Figure 1C). Consequently, our functional enrichment analysis showed that genes belonging to cell cycle checkpoint, DNA damage repair, ribosomal biogenesis and translational control were significantly enriched in induced transcriptome (Supplementary Table 3 ), whereas the genes involved in cell morphogenesis, cytokinesis, transcription, and protein binding were enriched in repressed transcriptome of KP1019 (Supplementary Table 4). The transcriptional induction of DNA damage repair genes (RNR1/RNR3/HUG1/RAD10/ $R A D 53 / R A D 54)$ and repression of cytokinesis, cell morphogenesis genes (DSE3/DSE4/EGT2) by KP1019 were in accordance with earlier studies [24, 27], and hence validated our transcriptome data (Supplementary Table 3, Supplementary Table 4). Further to understand the regulatory associations between different DEGs, we used GENEMANIA tool and constructed functional interaction network of KP1019 induced genes that were clustered based on their role in various biological processes such as cell cycle, cellular signaling, cell wall biogenesis, DNA modification, DNA repair, metal homeostasis, lipid and fatty acid metabolism, ribosomal biogenesis and translational regulation (Figure 1D). Altogether, our functional enrichment analysis of KP1019 transcriptome revealed several cellular processes that were targeted to exhibit its cytotoxicity.

\section{Intact cell wall integrity (CWI) pathway is essential for KP1019 tolerance}

Earlier, we have shown that KP1019 activates stress responsive Hog1 (p38) MAP kinase of High Osmolarity Glycerol (HOG) pathway [28]. Since HOG and CWI pathways cooperate with each other for relieving various stress conditions [33] and transcriptional induction of cell wall biogenesis genes by KP1019 (Figure 1D), we were encouraged to assess the role of CWI signaling pathway in its tolerance. Interestingly, our growth assay results showed that the null mutants of MAPKK kinase $(B C K 1)$, MAP kinase (SLT2), a transcriptional activator (SWI4), and glucanosyltransferase (GAS1) were found sensitive to KP1019 (Figure 2A, Supplementary Figure 2A), thereby indicating the prime role of intact CWI pathway in its tolerance. To reason the sensitivity of CWI mutants to KP1019, we supplemented growth medium with sorbitol, an osmotic stabilizer. Notably, osmotic stabilization of growth media with sorbitol significantly relieved the KP1019 effects (Figure 2B). Thus, it indicates that the sensitivity of CWI pathway null mutants might be credited to osmotic perturbation by KP1019. Further to test whether KP1019 activates CWI pathway, we performed western blotting analysis using an anti-p44/42 antibody that detects the dually phosphorylated Slt2 (Thr190/ Tyr192), a central MAP kinase of CWI pathway [34]. Surprisingly, we failed to observe significant activation of Slt2 MAP kinase upon KP1019 treatment (Figure $2 \mathrm{C})$. The levels of both phosphorylated $(\alpha-\mathrm{p} 44 / 42)$ and unphosphorylated ( $\alpha$-Mpk1) forms of Slt2 kinase were found similar in both untreated and KP1019 treated cells (Figure 2C). Hence, the differential activity of KP1019 towards the activation of these stress-responsive MAPKs Hog1 and Slt2 might be credited to their distinct functional role in cellular apoptosis and growth [35]. Furthermore to confirm that indeed KP1019 targets CWI pathway, we screened mutants of Rap1, a Repressor/Activator site binding Protein, for KP1019 tolerance (Supplementary Figure 2B). Intriguingly, rap $1 \Delta N$ cells that have defective cell wall [36] were found to be KP1019 sensitive, which was relieved upon sorbitol supplementation (Figure 2D). Collectively, our results indicate that KP1019 may affect directly or indirectly the cell wall and intact CWI pathway is required for its tolerance.

\section{KP1019 treatment alters $\mathrm{Ca}^{2+}$ ion homeostasis, increases lipid droplet accumulation, and Ethanolamine (ETA) supplementation remediates its cytotoxicity}

Recently, KP1019 has been shown to inhibit ATPdependent translocation of calcium $\left(\mathrm{Ca}^{2+}\right)$ ion in vitro 


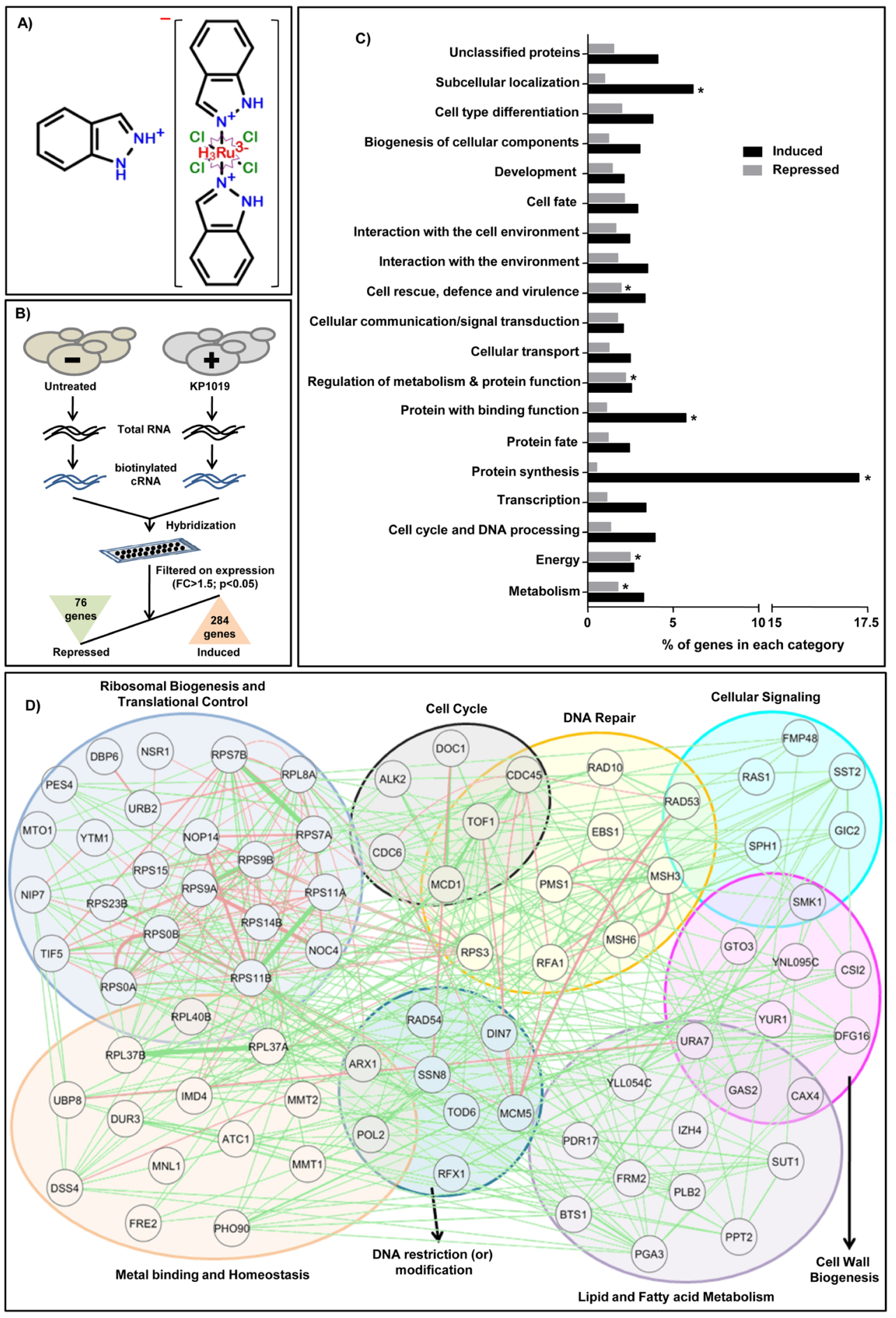

Figure 1: Global transcriptomics analysis upon KP1019 treatment. (A) Chemical structure of KP1019 (Indazolium trans[tetrachlorobis(1H-indazole)ruthenate (III)]). (B) Schematic representation of the procedure followed for the microarray analysis of yeast cells after KP1019 treatment. Total RNAs were extracted from wild-type cells (W1588-4C) that were left untreated (DMSO control) or treated with KP1019 $(50 \mu \mathrm{g} / \mathrm{ml} ; 3 \mathrm{~h})$, and then hybridized to yeast genome GeneChip arrays according to standard Affymetrix protocol. KP1019 treatment leads to significant upregulation of 284 genes and downregulation of 76 genes $(\mathrm{P}<0.05$; fold change $>1.5)$. (C) Functional classification of KP1019 transcriptome according to MIPS (The Munich Information Center for Protein Sequences) showed significant $\left({ }^{*} \mathrm{P}<0.05\right)$ enrichment of genes coding for cellular rescue/defense, metabolism, energy, and protein synthesis, etc. (D) Regulatory network analysis by GENEMANIA tool showed the reported genetic (green) and protein interactions (pink) exist among different genes induced by KP1019. The genes were clustered based on their functional role in various cellular processes including cell cycle, DNA repair, cell signaling, ribosomal biogenesis, lipid and metal homeostasis. 
by Sarco-endoplasmic reticulum $\mathrm{Ca}^{2+}$-ATPase (SERCA) pumps, which plays a critical role in intracellular calcium ion homeostasis [37]. To gain further insights into the mode of action of KP1019, we performed growth assay with null mutants of genes involved in $\mathrm{Ca}^{2+}$ ion homeostasis to identify genetic targets that are essential for KP1019 tolerance (Supplementary Figure 3A). Interestingly, our results showed that the null mutants of PMR1 (Golgi membrane P-type ATPase ion pump), CUP5 (Vacuolar-ATPase proton pump), CHC1 (Clathrin heavy chain), VRP1/OPI9 (Verprolin),
$R P S 27 B$ (Ribosomal protein of the small subunit), and VPS16 (member of Vacuolar protein sorting complex) were found sensitive to KP1019 (Figure $3 \mathrm{~A})$. The null mutants of $\mathrm{CHC1/CUP5/OPI9/PMR1/}$ $R P S 27 B / V P S 16 / V R P 1$ were reported to have increased accumulation of calcium ions [38], and their sensitivity to KP1019 was validated further by growth curve analysis (Supplementary Figure 3B). So, we propose that KP1019 treatment alters intracellular calcium ion homeostasis. The importance of $\mathrm{Ca}^{2+}$ ion levels in endoplasmic reticulum (ER) functioning [39] and ER-
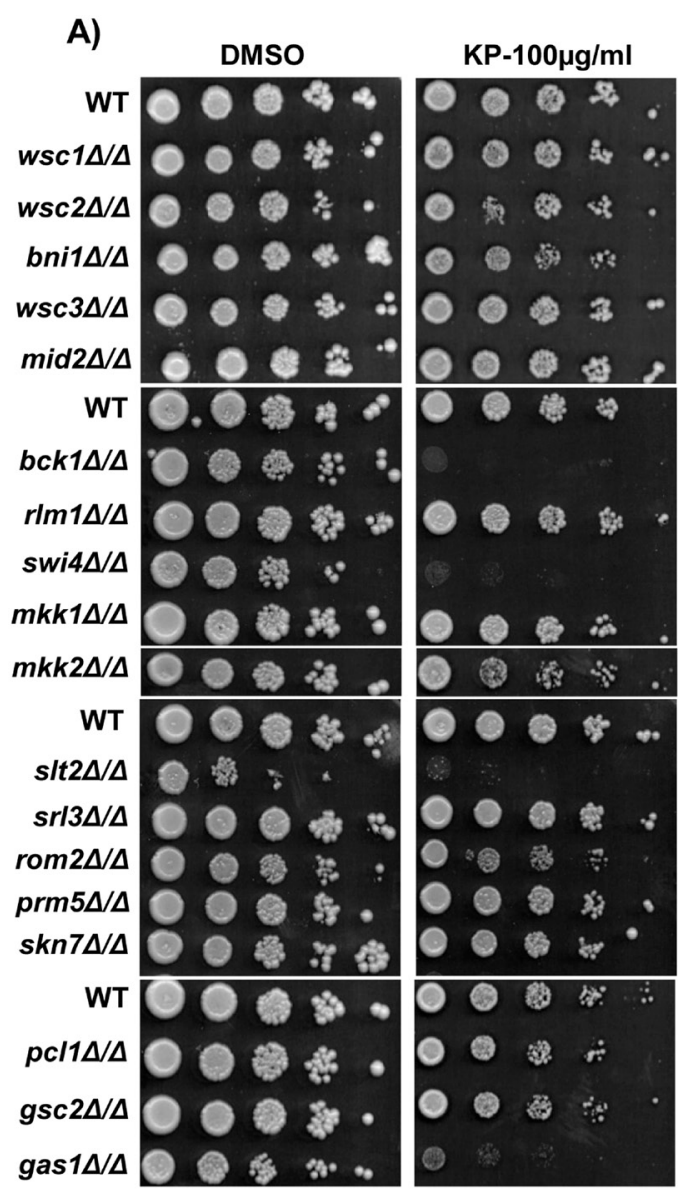
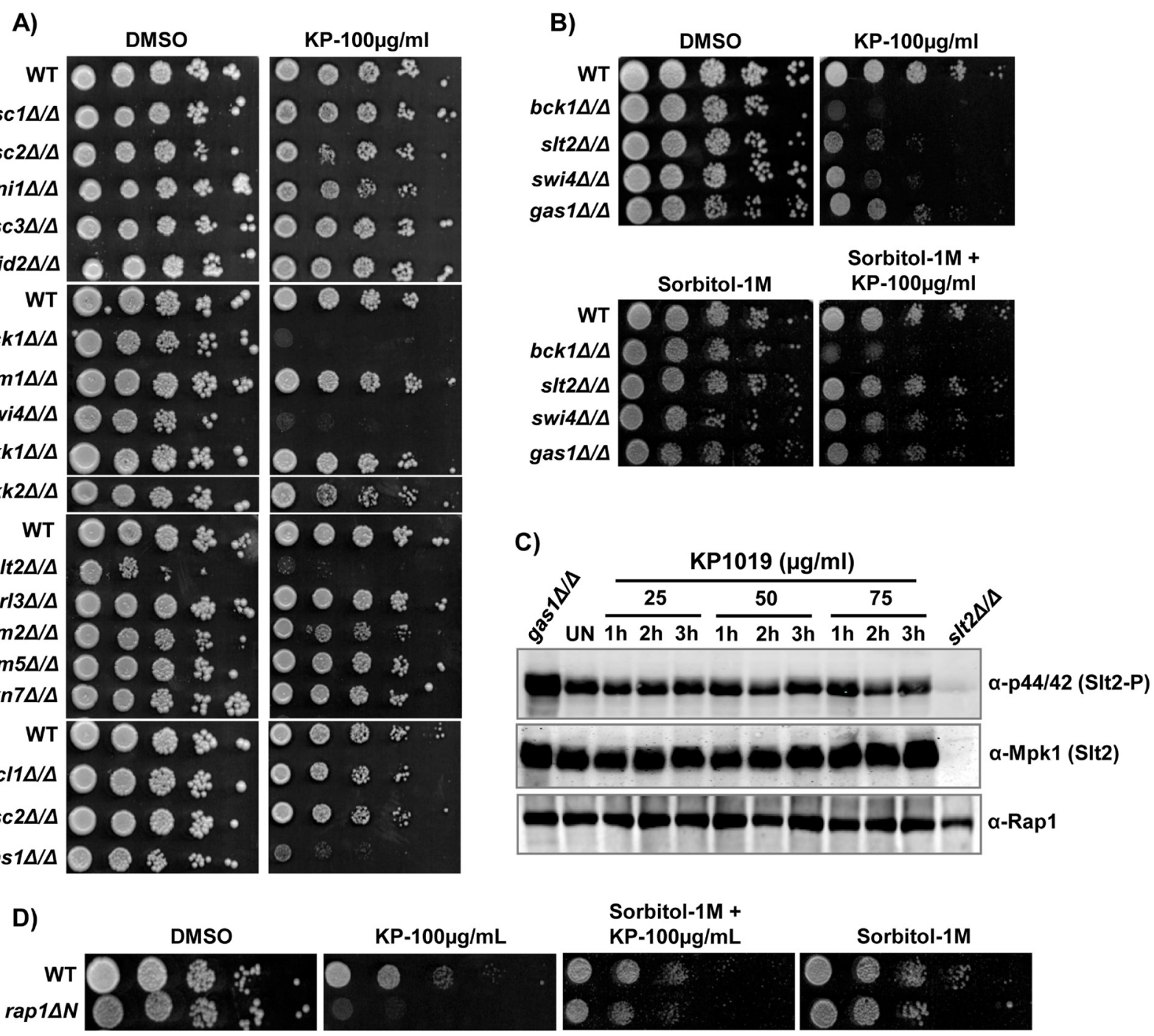

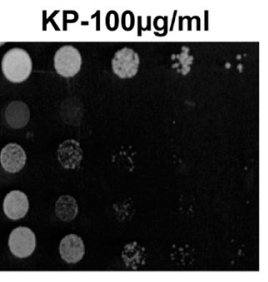

Sorbitol-1M +

Sorbitol-1M + $\mathrm{KP}-100 \mu \mathrm{g} / \mathrm{mL}$

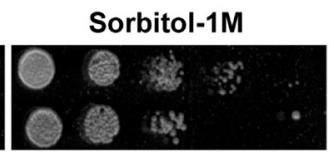

Figure 2: KP1019 mediates its cytotoxicity through cell wall integrity (CWI) pathway. (A and B) CWI pathway null mutants exhibited sensitivity to KP1019 (A) and supplementation of sorbitol as an osmotic stabilizer rescues the KP1019 sensitivity (B). Ten-fold serial dilutions of WT (BY4743) and indicated CWI pathway mutants were spotted onto SC-agar plates supplemented without (DMSO) or with KP1019 $(100 \mu \mathrm{g} / \mathrm{ml})$ and sorbitol (1M) in alone or the combination. The plates were imaged after $48 \mathrm{~h}$. (C) KP1019 treated cells do not activate Slt2 (Mpk1) MAP kinase. The exponentially growing wild-type (BY4743) yeast cells were left untreated or treated with different doses of KP1019 $(25,50$, and $75 \mu \mathrm{g} / \mathrm{ml})$ for indicated time points and the whole-cell protein extracts were subjected to immunoblotting analysis using indicated antibodies. Anti-Mpk1 and Anti-Rap1 signals were served as the control for checking Slt2 levels and protein loading respectively. The gas $1 \Delta$ cells that exhibit higher levels of phosphorylated Slt2 due to defective cell wall were used as a positive control. (D) Loss of Rap1 N-terminal region leads to increased KP1019 sensitivity. Ten-fold serial dilutions of WT (RAP1) and rap1 $\triangle N$

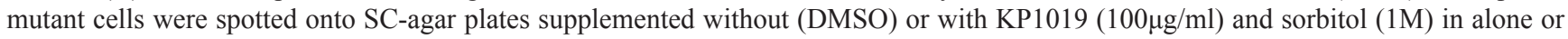
the combination. The plates were imaged after $48 \mathrm{~h}$. 
mediated effects of KP1339, a sodium salt of KP1019 [40], encouraged us to ascertain whether KP1019 has any effect on ER or not. We performed growth assay with the null mutants of IREI and $H A C 1$, the prime regulators and mediators known for activation of unfolded protein response (UPR)/ER-stress response genes in yeast [41], and found only ire1 $\Delta$ cells to be hypersensitive to KP1019 (Figure 3B). This further instilled in us to check the activation of UPR upon KP1019 treatment by checking the splicing of $H A C 1 \mathrm{mRNA}$ and expression of UPRE-lacZ (a reporter of UPR signaling) as indicated earlier [39]. Surprisingly, KP1019 treated cells failed to show increased levels of matured (spliced form) HACl mRNA (Figure 3C) and $\beta$-galactosidase activity (Figure 3D). Hence, our results indicated that the sensitivity of ire1 $\Delta$ cells to KP1019 might be due to their defective cell wall [42], depleted levels of membrane lipid component inositol [43], or credited to the indispensable role of Ire1 in lipid homeostasis [44] rather than activation of UPR in ER. In corroboration to this, KP1019 induced transcriptome showed the enrichment of genes involved in lipid and fatty acids (FAs) homeostasis (Figure 1D). To determine the possible effects of KP1019 on lipid homeostasis, we then performed growth assay with 147 null mutants of genes involved in lipids/FAs metabolism for KP1019 tolerance (Supplementary Figure 4). Interestingly, our results showed that the loss of genes involved in endocytosis (RVS167), GPI-anchor biosynthetic process (PER1), lipid/FAs transport (FAT1, GUP1), lipid/FAs metabolism (CSG2, ELO3, LCB5, OPI3, SUR2, VPS34), phosphate metabolism (SAC1, YTA7), sterol biosynthetic process (ERG3, ERG6), and transcriptional repression $(C Y C 8, T U P 1)$ results in moderate to severe sensitivity to KP1019 (Figure 3E, Supplementary Figure 5A), confirming that KP1019 mediates its toxicity through alteration of lipid/FAs metabolism and thus lipid homeostasis. Further to test the effect of KP1019 on lipid metabolism, we looked at the profile of intracellular neutral lipid stores (lipid droplets) using a cell-permeable lipophilic fluorescent dye BODIPY 493/503 that specifically stains the storage neutral lipids, lipid droplets (LDs) [45]. Notably, our results showed that KP1019 treatment leads to accumulation of intracellular lipid stores as evidenced by a drastic increase in the number of LDs per cell (Figure $3 \mathrm{~F}$, Supplementary Figure 5B) and hence indicates that KP1019 alters cellular lipid homeostasis. Although we showed that KP1019 does not induce ER stress (Figure 3D), the accumulation of LDs and sensitivity of lipid homeostasis genes in ER to KP1019 demonstrates that it might interfere with the structure and functions of ER. As lipid homeostasis is primarily controlled by the ER, we tested the effect of KP1019 on ER architecture using cells harboring ss-dsRed-HDEL reporter that stains both the cortical and nuclear ER [46]. To our surprise, the cells exhibited accumulation of LDs with retaining the intact architecture of both the cortical and nuclear ('bowtie' shaped) ER even after $6 \mathrm{~h}$ treatment with KP1019 (Figure 3G). Hence, we propose that KP1019 alters lipid homeostasis without affecting the architecture of ER.

Considering the conservation of lipid homeostasis pathways of yeast with mammalian models [47], we attempted to test the effect of KP1019 on intracellular lipid stores in HeLa cell lines. Amazingly, our results showed that KP1019 treatment induces the accumulation of LDs in HeLa cells too, similar to that of its effect in yeast cells (Figure 4A, 4B). These findings reasoned us to ask whether the LDs and enzymes involved in their formation play any role in KP1019 tolerance. So, we tested the effect of KP1019 on the quadruple

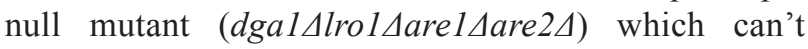
synthesize the neutral lipids and therefore lacks LDs [49]. Our results showed that the effect of KP1019 on LDs deficient quadruple null mutant is same as that of wild-type cells (Supplementary Figure 5C). This motivated us to check the effect of KP1019 on the mutant cells (ira24, pre94, pho904, snf24, spt214) that are known to have higher lipid content [50]. We found that ira24 cells are hypersensitive, whereas pre94 and spt214 exhibited mild sensitivity to KP1019 (Figure 4C), indicating that KP1019 effects are enhanced in the mutants with altered lipid homeostasis. Consequently, the null mutants of IRA2 and SPT21 showed a significant increase in LDs accumulation compared to wild-type untreated cells and the formation of LDs was further enhanced in these mutants (ira24, pre94, and spt214) after KP1019 treatment similar to that of wild-type cells (Supplementary Figure 6).

The identification of $O P I 3$, which catalyzes phosphatidylcholine (PC) biosynthesis via the Kennedy pathway, and VPS34, which synthesizes phosphatidylinositol (PI)-3-phosphate, here as genetic targets required for KP1019 tolerance (Figure 3E) encouraged us to check the effect of ethanolamine (ETA) supplementation on its activity. ETA is a precursor utilized by the Kennedy pathway for de novo synthesis of phosphatidylethanolamine (PE) and thus rescues most of the detrimental effects associated with low levels of phospholipids PE and PC [51]. Amazingly, ETA supplementation neutralized the toxic effects of KP1019 on wild-type yeast cells (Figure 4D, 4E) and the null mutants of lipid homeostasis (Figure 4F). In addition to the remediating effects on growth, ETA supplementation significantly decreased the accumulation of LDs induced by KP1019 treatment in yeast cells (Figure 4G, 4H), thus inferring the modulation of phospholipids synthesis and utilization by KP1019. Taken together, our results obtained both in yeast and HeLa cells strongly indicate that KP1019 treatment alters lipid homeostasis (biosynthesis, metabolism, and transport), and dietary ETA might interfere with its effectiveness. 
A)

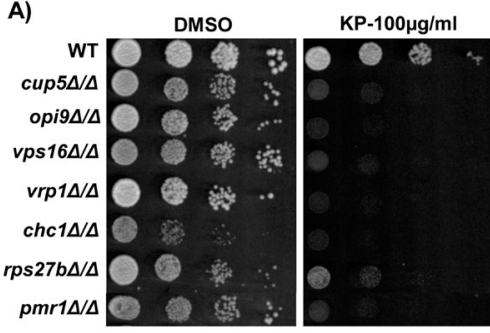

C)

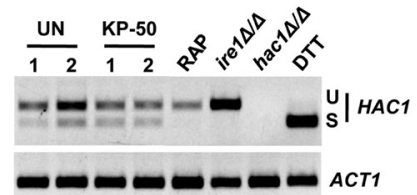

D)

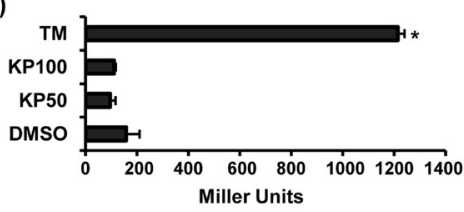

B)

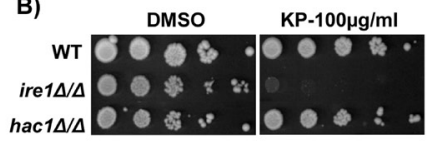

E)

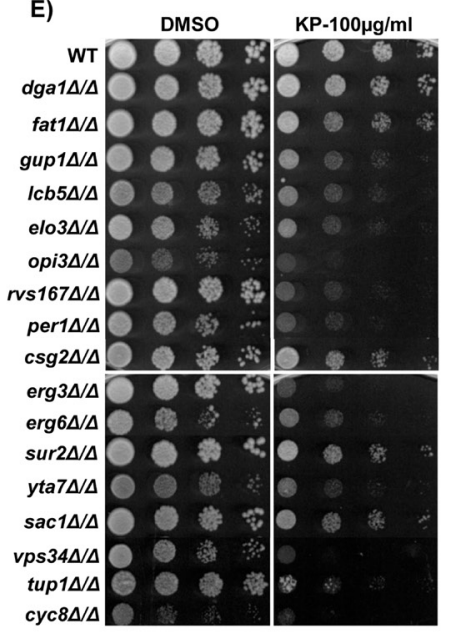

F)

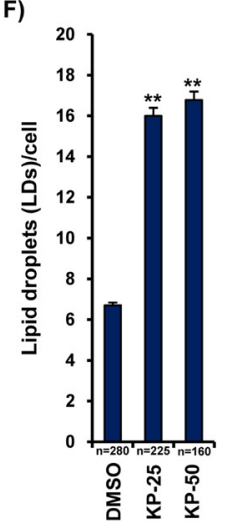

G)

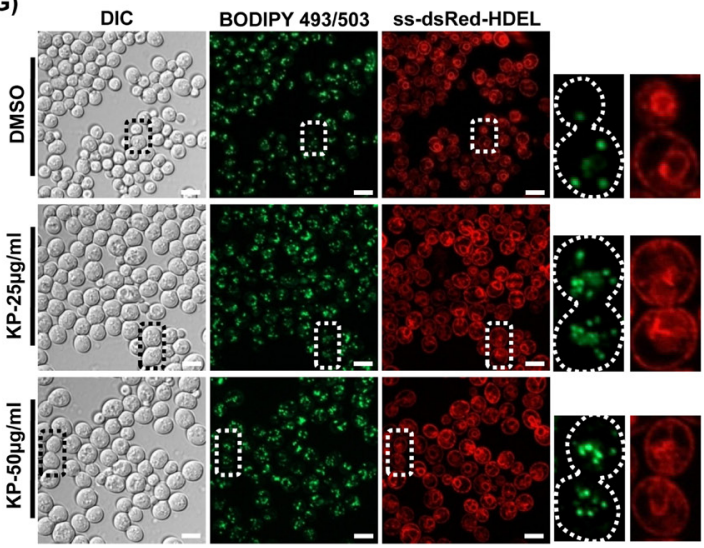

Figure 3: KP1019 treatment causes lipid droplets (LDs) accumulation. (A and B) The gene products involved in $\mathrm{Ca}^{2+}$ ion homeostasis (A) and Irel kinase involved in unfolded protein response (UPR) are required for KP1019 tolerance (B). Ten-fold serial dilutions of WT and indicated mutants were spotted in absence or presence of KP1019 and the growth was monitored after 48h. (C) KP1019 does not induce maturation of HAC1 mRNA. Total RNAs isolated from the wild-type (W1588-4C) cells that were left untreated or treated with KP $(50 \mu \mathrm{g} / \mathrm{ml} ; 3 \mathrm{~h})$, rapamycin-RAP $(200 \mathrm{nM} ; 3 \mathrm{~h})$, and dithiothreitol-DTT $(2 \mathrm{mM} ; 1 \mathrm{~h})$ were reverse transcribed to cDNA. The maturation of HAC1 was assessed by detecting levels of both the unspliced (U) and spliced (S) forms of HAC1 mRNA using intronspecific splicing primers. Cells treated with DTT, an ER stress inducer were served as a positive control, whereas ire 1 $\triangle$ cells were served as a negative control. hac1 $\triangle$ cells were used to check the specificity of primers used. ACTIN levels were used as control. (D) KP1019 does not alter UPRE activity. The wild-type (BY4741) yeast cells harboring UPRE::lacZ reporter plasmid were grown to exponential phase and then left untreated (DMSO solvent control) or treated with $\mathrm{KP} 1019(50,100 \mu \mathrm{g} / \mathrm{ml})$ for $3 \mathrm{~h}$ and Tunicamycin-TM $(1 \mu \mathrm{g} / \mathrm{ml} ; 1 \mathrm{~h})$. $\beta$-galactosidase activity was measured using ONPG as a substrate and represented the results in terms of Miller units. The results are Mean \pm SEM, from two independent experiments each performed in triplicate. ${ }^{*} \mathrm{P}<0.05$ considered significant compared to DMSO control (Student's t-test). (E) KP1019 alters lipid homeostasis, and the null mutants of genes involved in lipid biosynthesis and metabolism are sensitive to KP1019.

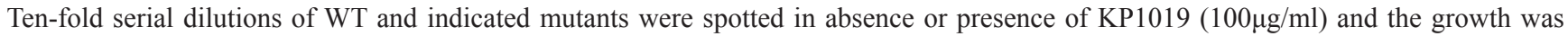
monitored after 48h. (F) Quantification of KP1019-induced LDs formation in yeast cells. The wild-type (BY4743) yeast cells were grown to exponential phase and left untreated (DMSO control) or treated with KP1019 $(25,50 \mu \mathrm{g} / \mathrm{ml})$ for $3 \mathrm{~h}$, then stained with BODIPY $493 / 503$ dye to visualize the LDs under ApoTome microscope. The LDs stained with BODIPY 493/503 in ApoTome images were counted and represented as the number of LDs per cell (Mean \pm SEM; $n=280$ for DMSO, 225 for KP25, and 160 for KP50). ${ }^{* *} \mathrm{P}<0.001$ (compared to DMSO control) were considered significant (Student's t-test). (G) KP1019 treatment induces accumulation of LDs in yeast cells without altering ER architecture. Wild-type yeast cells harboring ss-DsRed-HDEL reporter (stains both cortical and nuclear ER) were grown to exponential phase and left untreated (DMSO control) or treated with KP1019 $(25,50 \mu \mathrm{g} / \mathrm{ml})$ for $6 \mathrm{~h}$, then stained with BODIPY $493 / 503$ dye to visualize the LDs. Cells treated with KP1019 had shown increased cell size and the number of LDs (compared to control) with retaining the intact cortical and nuclear ('bowtie' shaped) ER architecture. The representative images from three independent experiments were shown. Scale bar represents $5 \mu \mathrm{m}$. 
A)

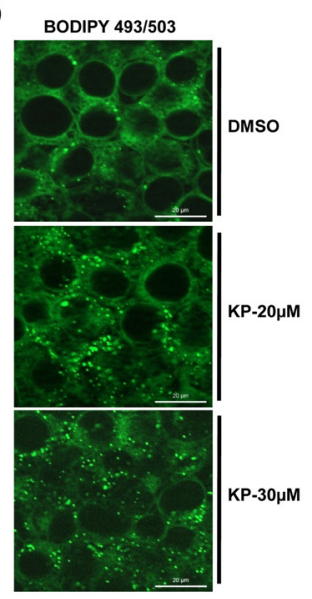

E)

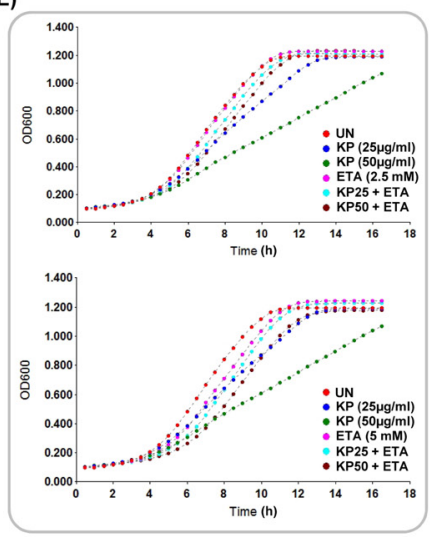

G)

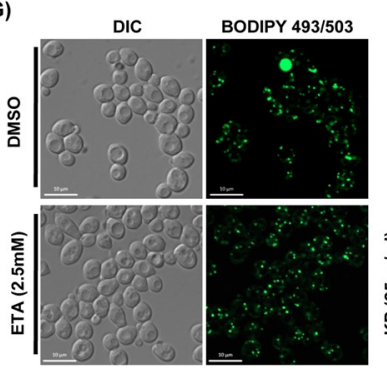

B)

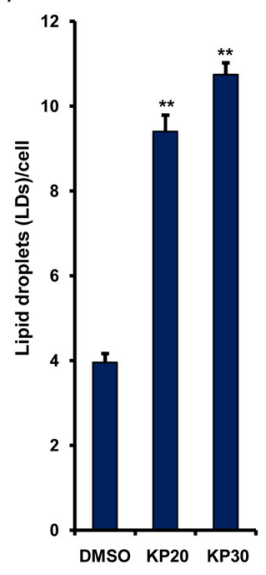

C)

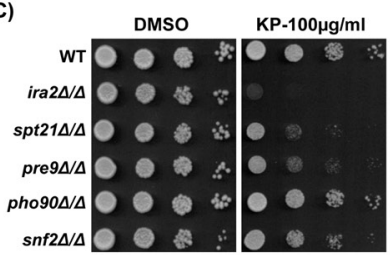

D)

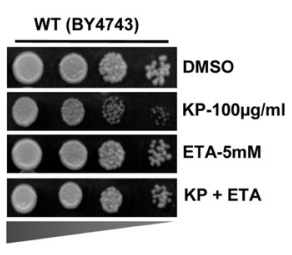

F)

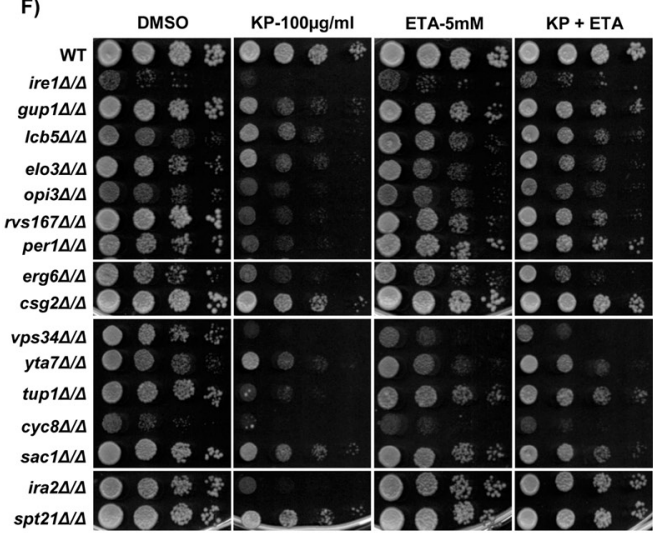

H)
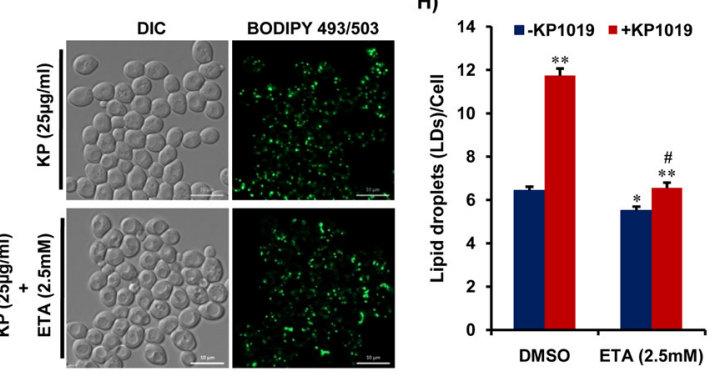

Figure 4: Supplementation of ethanolamine (ETA) suppresses KP1019-induced LDs accumulation and toxicity. (A and B) Human cervical cancer (HeLa) cells exhibit increased LDs upon KP1019 treatment. HeLa cells treated with either DMSO (solvent control) or KP1019 $(20,30 \mu \mathrm{M})$ were stained with BODIPY 493/503 dye and LDs were visualized using ApoTome microscope. The

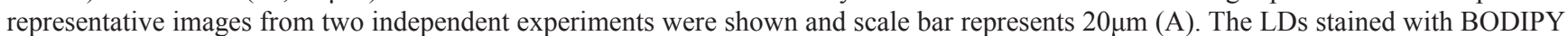
$493 / 503$ dye in (A) were counted and represented as number of LDs per cell ( $\mathrm{n}=414$; Mean $\pm \mathrm{SEM}$ ). ${ }^{* *} \mathrm{P}<0.001$ (compared to DMSO control) were considered significant (Student's t-test) (B). (C) KP1019 is more effective in the mutants with higher lipid content. Ten-fold serial dilutions of WT and indicated mutants (with increased lipid content) were spotted in absence or presence of KP1019 (100 $\mu \mathrm{g} / \mathrm{ml})$ and the growth was monitored after 48h. (D and F) Ethanolamine (ETA) supplementation neutralizes the KP1019-induced cytotoxicity. Ten-fold serial dilutions of wild-type (WT) BY4743 cells (D) and indicated KP1019 sensitive null mutants of lipid homeostasis (F) were spotted in the absence (DMSO control) or presence of KP1019 $(100 \mu \mathrm{g} / \mathrm{ml})$ and ETA $(5 \mathrm{mM})$ in alone and combination. The growth was monitored after 48h. (E) KP1019-induced toxicity is suppressed in the presence of ETA. The exponentially growing wild-type (BY4743) cells were treated with either DMSO solvent (control) or indicated doses of KP1019 (KP) and ETA in alone or combination. The growth was monitored in terms of absorbance (OD600) for indicated period using a plate reader. (G and $\mathbf{H})$ ETA supplementation remediates KP1019induced LDs accumulation. The exponentially growing wild-type (BY4743) yeast cells were treated with either DMSO (solvent control) or $\mathrm{KP} 1019(25 \mu \mathrm{g} / \mathrm{ml})$ and ETA $(2.5 \mathrm{mM})$ in alone and combination for $3 \mathrm{~h}$. The cells were stained with BODIPY $493 / 503$ dye and LDs were visualized using ApoTome microscope. The representative images from two independent experiments were shown and scale bar represents $10 \mu \mathrm{m}(\mathrm{G})$. The LDs stained with BODIPY 493/503 dye in $(\mathrm{G})$ were counted and represented as the number of LDs per cell ( $\mathrm{n}=150$; Mean \pm SEM). ${ }^{*} \mathrm{P}<0.01,{ }^{* *} \mathrm{P}<0.001$ (compared to DMSO control) and ${ }^{*} \mathrm{P}<0.001$ (compared to only KP1019 treated) were considered significant (Student's t-test) $(\mathrm{H})$. 
KP1019 antagonizes the effects of Rapamycin, an inhibitor of TOR (Target of Rapamycin) pathway

The transcription of ribosomal protein (RP) genes is controlled by TOR pathway in accordance with the growth of cells, and rapidly downregulated in response to a variety of environmental stress stimuli that inhibits the cellular growth such as heat shock, nutrients starvation, and osmotic stress [52-54]. Despite the fact that KP1019 inhibits the growth of yeast cells (Supplementary Figure 1) and induce osmotic stress [28], our genome-wide transcriptome analysis of wild-type yeast cells treated with a sublethal dose of KP1019 showed upregulation of several RP genes (Figure 5A), and accordingly exhibited significant functional enrichment of genes involved in ribosomal biogenesis and translational control (Figure 1D, Supplementary Table 3). As Sfp1 is localized to the nucleus under optimal growth conditions and majorly regulates the transcriptional induction of RP genes, first we checked its localization upon KP1019 treatment using cells harboring GFP-tagged Sfp1 [55]. As expected, Sfp1-GFP is localized to the nucleus in exponentially growing wild-type cells that were left untreated for $3 \mathrm{~h}$ (Figure 5B). In contrast, our microscopy results showed that Sfp1-GFP is localized to the nucleus within $1 \mathrm{~h}$ treatment of early exponential phase cells with KP1019 compared to untreated (DMSO control) cells (Figure 5B). Hence, our findings indicate that the early nuclear localization of stress-responsive Sfp1 is in agreement with the transcriptional induction of RP genes upon KP1019 treatment. Since the nuclear localization of Sfp1 and transcriptional induction of RP genes is strongly correlated with the active TOR pathway signaling [56, 57], we then speculated that TOR pathway is functional in the cells stressed with KP1019. To check our hypothesis, we tested the levels of phosphorylated Sch9, a well-known substrate of yeast TOR complex 1 (TORC1), by immunoblotting analysis using Anti-S758-P antibody (gifted by Robbie J. Loewith) [58]. Interestingly, the levels of phosphorylated Sch9 were found to be similar in both untreated and KP1019 treated cells (Figure 5C), thus indicating that TORC1 is active and unaffected by the treatment with growth-inhibiting doses of KP1019.

Since TOR is active in KP1019 treated cells, we then performed genetic screening with the null mutants of TOR pathway to test its role in providing KP1019 tolerance and found none of them sensitive to KP1019 treatment (Supplementary Figure 7A). Moreover, the null mutants of TOR pathway showed activation of Rad53 kinase (Supplementary Figure 7B), increase in the cell size and formation of LDs (Supplementary Figure 7C, Supplementary Figure 7D) similar to that of wild-type cells upon KP1019 treatment. Therefore, our results illustrate that functional TOR signaling is not essential for exhibiting the toxic effects of KP1019. Further to understand the effects of KP1019 under TOR inactive condition, we performed growth assay with TOR pathway null mutants in the presence of both KP1019 and rapamycin (RAP), an allosteric inhibitor of Tor1 kinase and TOR pathway activation [59]. Intriguingly, we observed that the cytotoxic effects of RAP induced by TOR inactivation were suppressed by KP1019 in a dose-dependent fashion (Figure 5D), which is in accordance with our above results. This suggests that KP1019 interferes directly/ indirectly with the processes affected due to inactivation of TOR by RAP. Moreover, the resultant effect upon cotreatment with RAP and KP1019 in liquid media is found to be dependent on their dose ratio since we observed both the additive (Supplementary Figure 7E) and slight antagonistic activity (Supplementary Figure 7F) with their different dose combinations. Given that RAP and other mTOR inhibitors are in clinical testing as anticancer agents, we were motivated to check the outcome of RAP and KP1019 co-treatment on the HeLa cells survival using MTT assay. Surprisingly, the combination of RAP and KP1019 showed a mild additive cytotoxic effect as indicated by the significant decrease in mean $\%$ survival of HeLa cells compared to only KP1019 treatment (Figure 5E). Altogether, these findings demonstrated that KP1019 do not require functional TOR signaling for mediating its cytotoxicity and its cytotoxicity potential can be modulated in the presence of mTOR inhibitors.

\section{KP1019 alters metal homeostasis, and the presence of various metal ions differentially modulates the KP109-induced cytotoxicity}

In continuation with the earlier report that showed an increase in $\mathrm{Cu}$ densities by KP1019 in vitro [60], our KP1019 transcriptome also envisaged upregulation of metal homeostasis genes (Figure 1D). Here to check the effect of KP1019 on metal ion homeostasis, we analyzed the growth of yeast cells upon co-treatment with KP1019 and various metal ions. For this, we first performed growth assay with wild-type cells in the presence of different metal cation chlorides to determine their effective dose (Supplementary Figure 8). Next, we monitored the effect of KP1019 and different metal cations $\left(\mathrm{Al}^{3+}, \mathrm{Ca}^{2+}, \mathrm{Cd}^{2+}\right.$, $\mathrm{Co}^{2+}, \mathrm{Cu}^{2+}, \mathrm{Fe}^{2+}, \mathrm{Mg}^{2+}, \mathrm{Mn}^{2+}, \mathrm{Na}^{+}, \mathrm{Ni}^{2+}$, and $\mathrm{Zn}^{2+}$ ) alone or in combination on the growth of yeast cells by growth assays. Interestingly, the combination of KP1019 with $\mathrm{Al}^{3+}, \mathrm{Ca}^{2+}, \mathrm{Cu}^{2+}, \mathrm{Mg}^{2+}, \mathrm{Mn}^{2+}, \mathrm{Na}^{+}$, and $\mathrm{Cd}^{2+}$ was found to be lethal and exhibited enhanced cytotoxicity (Figure $6 \mathrm{~A})$. In contrast, the presence of $\mathrm{Fe}^{2+}$ ions neutralized the cytotoxic effects of KP109 on yeast cells (Figure $6 \mathrm{~B})$. Our growth curve analysis also confirmed that the toxicity potential of KP1019 is augmented in the presence of abovementioned metal ions except for $\mathrm{Fe}^{2+}$, which reduced the KP1019 toxicity (Supplementary Figure 9). These results reasoned us to ask whether rutheniumbased KP1019 interacts with other metal cations or not. For interaction studies, we monitored the characteristic 
A)

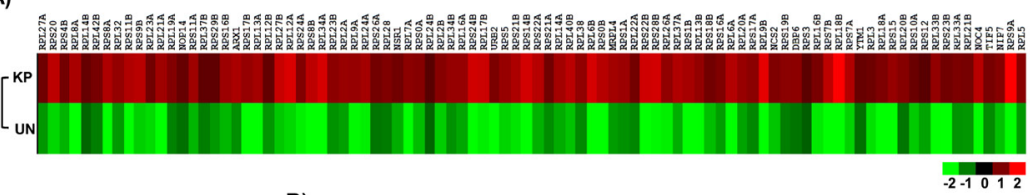

B)
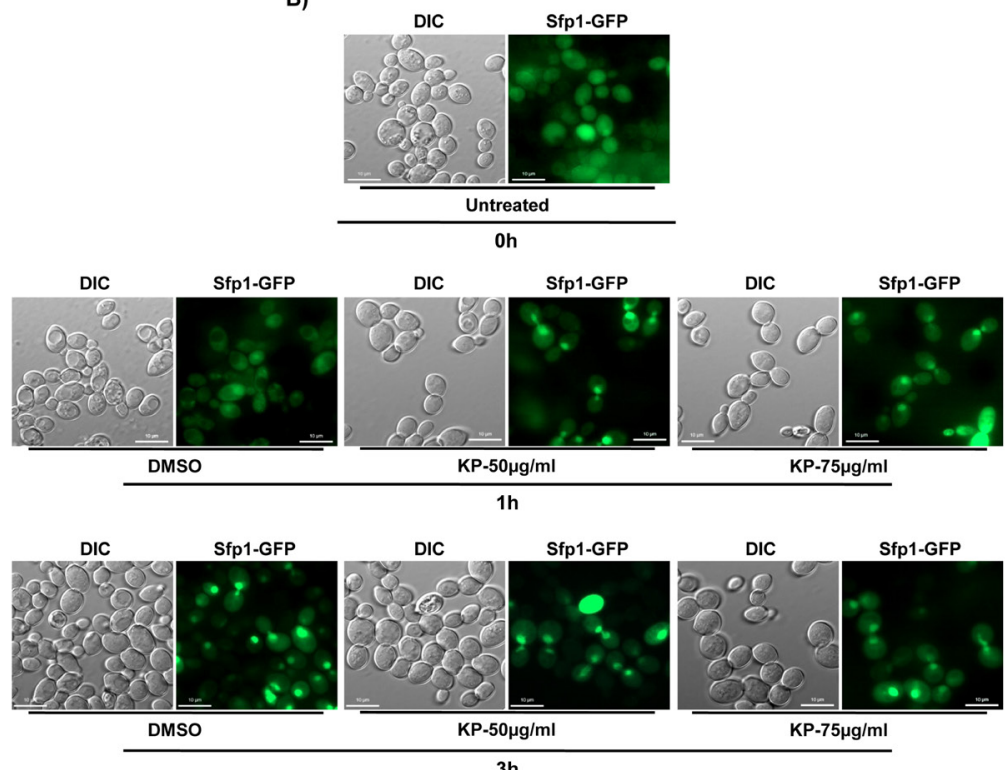

C)

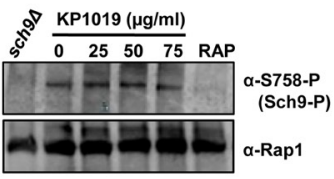

E)

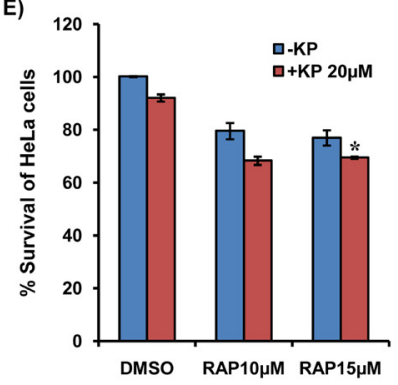

D)

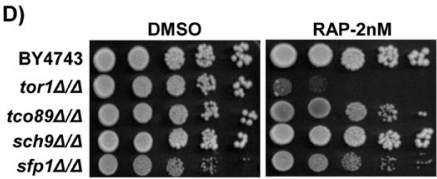

sfp1 $1 \Delta / \Delta$

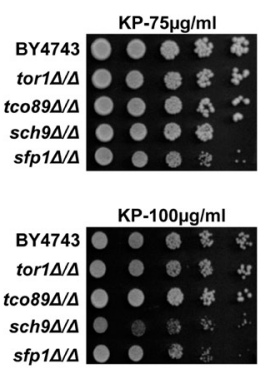

KP 75 H + RAP-2nM

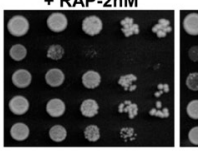

$\mathrm{KP}-100 \mu \mathrm{g} / \mathrm{ml}$ $\mathrm{KP}-100 \mu \mathrm{g} / \mathrm{ml}$
+ RAP-2nM

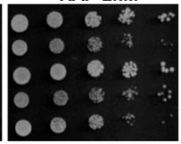

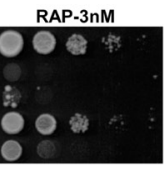

$\mathrm{KP}-75 \mu \mathrm{g} / \mathrm{ml}$ + RAP-3nM

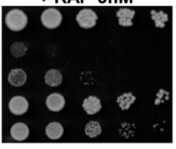

$\mathrm{KP}-100 \mathrm{\mu g} / \mathrm{ml}$ + RAP-3nM

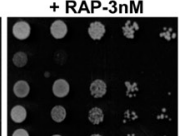

Figure 5: KP1019 treatment induces ribosomal biogenesis genes and modulates the effect of Rapamycin, an inhibitor

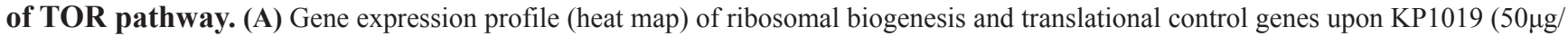
$\mathrm{ml}$ ) treatment. The average normalized expression values $\left(\log _{2}\right)$ for each gene from two independent experiments were illustrated by redgreen color scale. (B) KP1019 treatment induces the early nuclear localization of Sfp1, a critical regulator of ribosomal biogenesis genes. Wild-type (BY4743) cells harboring GFP-tagged Sfp1 were grown to early exponential phase (OD600: 0.8-1) and left untreated (DMSO) or treated with KP1019 $(50,75 \mu \mathrm{g} / \mathrm{ml})$. The localization of Sfp1 was monitored after $1 \mathrm{~h}$ and $3 \mathrm{~h}$ of KP1019 treatment using ApoTome microscope. The KP1019 treated cells known to have nuclei spanning bud neck ('bowtie' phenotype) and the bowtie-shaped Sfp1-GFP signals upon KP1019 treatment indicates its nuclear localization. The representative images from three independent experiments were shown. Scale bar represents 10 $\mu \mathrm{m}$. (C) TOR pathway is functional/active in cells treated with KP1019 as indicated by Sch9 phosphorylation.

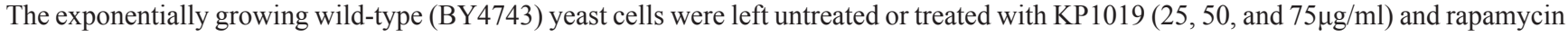
(200nM; RAP) for $3 \mathrm{~h}$. The whole-cell protein extracts were subjected to immunoblotting analysis of Sch9 phosphorylation using AntiS758-P antibody. Anti-Rap1 signals were served as the control for checking protein loading. The $s c h 94$ and RAP-treated cells were used as negative controls. (D) KP1019 antagonizes the effects of rapamycin (RAP), an inhibitor of the TOR pathway. Ten-fold serial dilutions of wild-type (BY4743) and indicated TOR pathway null mutants were spotted onto SC-agar plates supplemented with DMSO or KP1019 and RAP at an indicated doses in alone or the combination. The plates were imaged after 72h. (E) The cytotoxicity of KP1019 in HeLa cells was slightly enhanced in combination with RAP, an immunosuppressant. The viability of HeLa cells treated with KP019 $(20 \mu \mathrm{M})$ and RAP $(10$, $15 \mu \mathrm{M})$ in alone or combination was analyzed by MTT assay, and the results were represented as \% survival (compared to DMSO control). The values are Mean \pm SEM, from two independent experiments each performed in duplicate. ${ }^{*} \mathrm{P}<0.05$ considered significant compared to DMSO control (Student's t-test). 
UV-Visible absorption (360 and 420nm) spectra of KP1019 in the absence and presence of metal ions whose combinations adversely affected its toxicity. Notably, the combination of phosphate-buffered (Supplementary Figure $10 \mathrm{~A}$ ) or aqueous (Supplementary Figure 10B) solutions of metal ions $(400 \mu \mathrm{M})$ and $\mathrm{KP} 1019(65 \mu \mathrm{M})$ showed changes in neither color nor the UV-Vis absorption spectra after $5 \mathrm{~h}$ incubation at $37^{\circ} \mathrm{C}$. However, the presence of $\mathrm{Fe}^{2+}$ $(400 \mu \mathrm{M})$ altered the characteristic absorption spectra of KP1019 in buffered condition (Supplementary Figure $10 \mathrm{~A})$ indicating the possible formation of its new species that is not/less toxic to yeast cells (Figure 6B).

Given that KP1019 alters Fe distribution without affecting its cellular content in vitro [60], the fate of $\mathrm{Fe}$ in yeast cells upon KP1019 treatment is unknown. To test whether KP1019 alters intracellular iron levels, we performed growth assay with null mutants of iron ion homeostasis genes encoding iron transporters and ferric reductases for its tolerance (Supplementary Figure 11A). Our results indicated that KP1019 does not interfere with intracellular iron ion levels as none of the tested mutants were sensitive to KP1019 (Supplementary Figure 11A). Moreover, the supplementation of $\mathrm{Fe}^{2+}$ relieves the effect of KP1019 on wild-type and null mutants of an irontransport system to the same extent (Supplementary Figure 11B). So, it demonstrates that the diminished effects of KP1019 in the presence of iron ions could be accounted to its chemical inactivation (Supplementary Figure 10A) or functional antagonism with Fe rather than their competitive uptake through the iron-transport system (Supplementary Figure 11B). In contrast, our results with real-time analysis of growth in liquid media showed that the loss of Fe transport system (FET3/FET5) resulted in partial reduction of KP019 effectiveness compared to wild-type cells (Supplementary Figure 11C), thus revealing the role of iron-transport system in mediating the KP1019-induced toxicity probably through alteration of metal ion homeostasis [61].

Given that KP1019 induces oxidative stress and suppression of its toxicity by antioxidants in human cell lines [23], we asked whether supplementation of antioxidants can rescue KP1019 effects in yeast. In good agreement with the earlier reports, our results showed that the toxic effects of KP1019 were suppressed in the presence of biological antioxidant GSH (reduced glutathione) and its precursor N-acetylcysteine (NAC) in vivo (Supplementary Figure 11D, Supplementary Figure 11E). This suggests that KP1019 might be depleting the GSH levels and thus perturbing the redox homeostasis to mediate its toxicity (Supplementary Figure 11D, Supplementary Figure 11E). Although there is no activation of oxidative stress responsive genes including Yap1, the transcriptional induction of environmental stress response and cellular defense genes by KP1019 reasoned us to speculate that its enhanced toxicity with various metal ions could be due to further increase in the oxidative burden of yeast cells (Figure 1C).
For correlating above findings to KP1019 anticancer activity, we tested the effect of KP1019 treatment in combination with metal ions on HeLa cells viability by MTT assay. Interestingly, the cytotoxicity potential of KP1019 was significantly enhanced in the presence of metal ions such as $\mathrm{Al}^{3+}, \mathrm{Cd}^{2+}, \mathrm{Cu}^{2+}, \mathrm{Mn}^{2+}$, and $\mathrm{Zn}^{2+}$, while $\mathrm{Ca}^{2+}, \mathrm{Co}^{2+}, \mathrm{Na}^{+}, \mathrm{Ni}^{2+}$ slightly increased its cytotoxicity compared to only KP1019 treated cells (Figure 6C). Furthermore, the morphology of HeLa cells upon treatment with KP1019 and metal cations in combination showed the apoptotic features compared to their individual treatments (Supplementary Figure 12). Collectively, our findings indicate that KP1019 treatment alters metal ion homeostasis and its anticancer potential is significantly augmented in the presence of various metal cations.

\section{Histone $\mathrm{H} 3$ and $\mathrm{H} 4$ residues play a critical role in the regulation of KP1019-induced cytotoxicity}

Histones are highly conserved proteins that undergo a variety of post-translational modifications (PTMs), which are majorly concentrated on amino termini (tails) of histone $\mathrm{H} 3$ and $\mathrm{H} 4$ additional to some PTMs occur in their structural domains, required for chromatin plasticity and thus coordinating gene regulation mechanisms [62]. Despite the fact that we could not see significant changes in the levels of global histone modifications upon KP1019 treatment earlier [24], here we attempted to analyze the chromatin features of KP1019 transcriptome using ChromatinDB database. Interestingly, we found that the promoters of genes induced by KP1019 treatment have depleted occupancy of all four core histones with the enrichment of transcriptionally active acetylation marks (Supplementary Figure 13A), while its repressed transcriptome does not exhibit enrichment of any chromatin features (Supplementary Figure 13B). This suggests that KP1019 treatment affects the occupancy and PTMs of histones at specific gene promoters rather than entire genome for orchestrating transcriptional regulation. The ability of KP1019 to interact with histone $\mathrm{H} 3$ and cause eviction of histones from nucleosome in vitro [24], further fuelled our quest for unraveling the role of histone residues and their respective PTMs in translating KP1019-mediated cellular effects. To test this, we employed high-throughput screening of synthetic histone $\mathrm{H} 3$ and $\mathrm{H} 4$ mutants library derived by Dai et al. [63] for KP1019 tolerance (sensitive/resistant) (Figure 7A). The doses of KP1019 for screening the histone library were obtained by growth assay with wild-type cells. Accordingly, we used $50 \mu \mathrm{g} / \mathrm{ml}$ and $100 \mu \mathrm{g} / \mathrm{ml}$ of KP1019 for identifying the sensitive and resistant mutants respectively (Supplementary Figure 14A). Remarkably, our high-throughput screening of histone $\mathrm{H} 3 / \mathrm{H} 4$ mutants library with KP1019 (Supplementary Figure 14B) led to the identification of $86(\approx 34.5 \%) \mathrm{H} 3$ and $79(\approx 46 \%) \mathrm{H} 4$ mutants that demonstrated altered phenotypes to KP1019 
A)
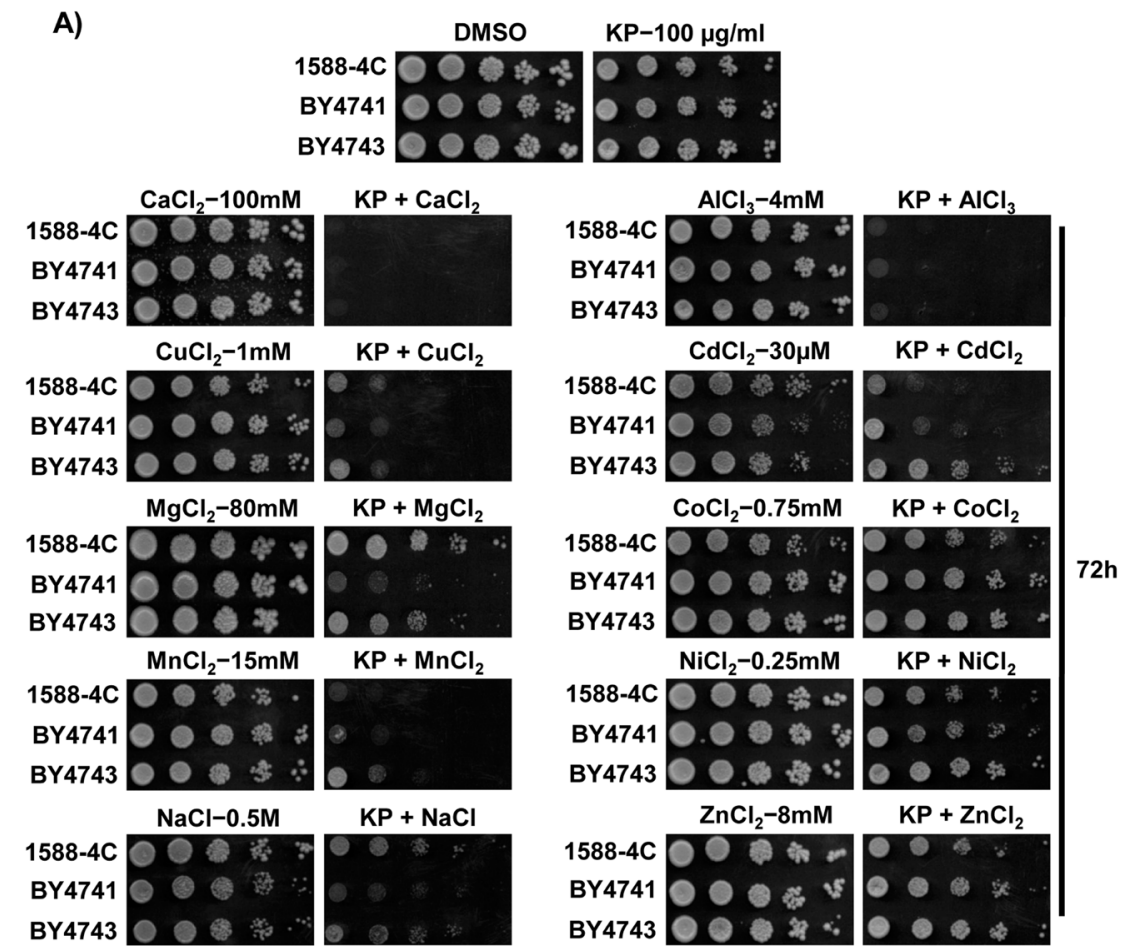

B)
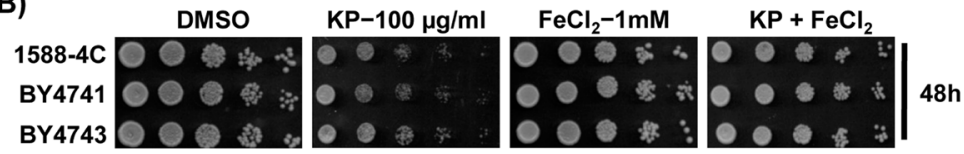

C)

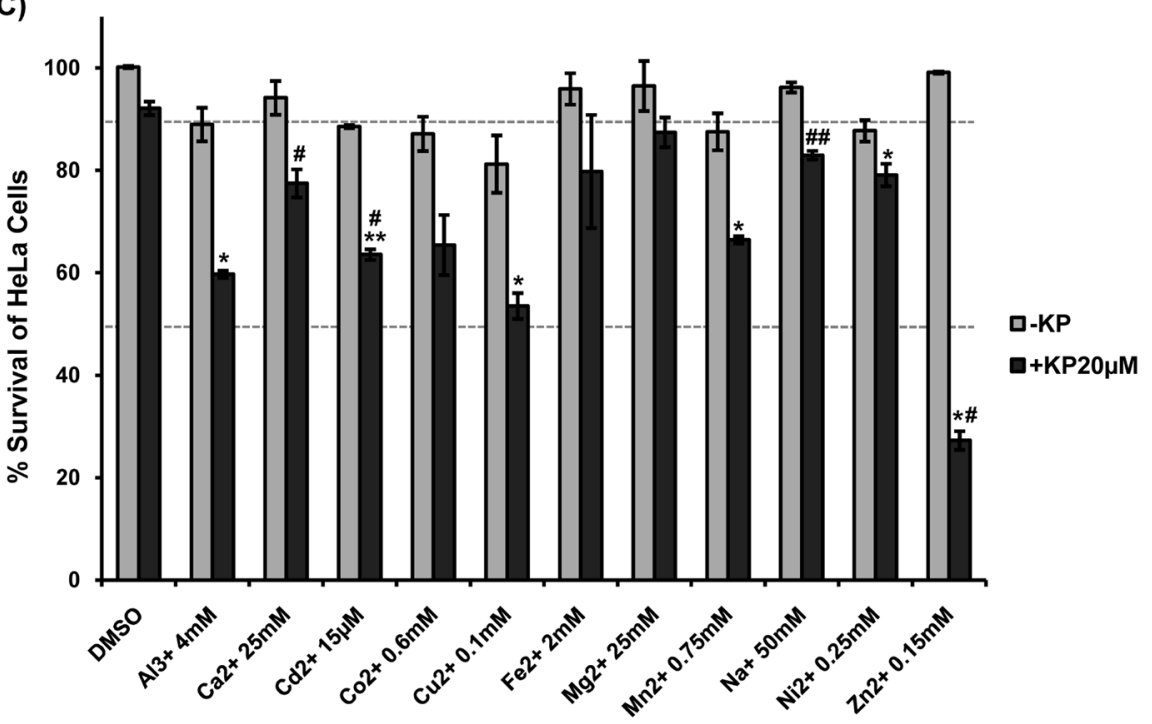

Figure 6: KP1019 alters metal homeostasis, and its cytotoxicity potential is modulated significantly in the presence of different metal cations. (A and B) The effect of KP1019 was enhanced in the presence of various metal cations and suppressed by $\mathrm{Fe}^{2+}$ ions. Ten-fold serial dilutions of indicated wild-type yeast cells were spotted onto SC-agar plates supplemented with DMSO, indicated metal cation chlorides (A) or iron $\left(\mathrm{Fe}^{2+}\right)$ chloride (B) in alone or combination with KP1019 $(100 \mu \mathrm{g} / \mathrm{ml})$. The plates were imaged after indicated time. (C) KP1019 exhibit synergetic cytotoxicity with metal cations in human cervical cancer (HeLa) cells. The viability of HeLa cells treated with KP019 $(20 \mu \mathrm{M})$ and metal cation chlorides $\left(\mathrm{Al}^{3+}, \mathrm{Ca}^{2+}, \mathrm{Cd}^{2+}, \mathrm{Co}^{2+}, \mathrm{Cu}^{2+}, \mathrm{Fe}^{2+}, \mathrm{Mg}^{2+}, \mathrm{Mn}^{2+}, \mathrm{Na}^{+}, \mathrm{Ni}^{2+}\right.$, and $\left.\mathrm{Zn}^{2+}\right)$ at indicated doses in alone or combination was analyzed by MTT assay, and the results were represented as $\%$ survival (compared to DMSO control).

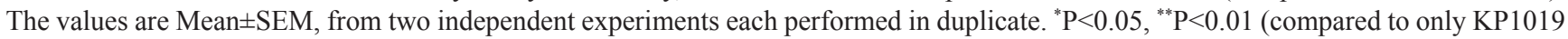
treated) and ${ }^{\#} \mathrm{P}<0.05,{ }^{\#} \mathrm{P}<0.01$ (compared to only respective metal treated) were considered significant (two-tailed, paired Students t-test). 
(Supplementary Table 5, Supplementary Table 6), and the results were summarized in Figure 6B. Although we found the total number of KP1019 sensitive $(\approx 74.5 \%$ of all hits for $\mathrm{H} 3$ and $\approx 24 \%$ of all hits for $\mathrm{H} 4$ ) and resistant $(\approx 25.5 \%$ of all hits for $\mathrm{H} 3$ and $\approx 76 \%$ of all hits for $\mathrm{H} 4)$ mutants were almost equal $(\approx 82)$, it is evident from our results that more robust KP1019 sensitive phenotypes were identified for $\mathrm{H} 3$ mutants and resistant phenotypes for $\mathrm{H} 4$ mutants relative to $\mathrm{H} 4$ and $\mathrm{H} 3$ respectively (Figure 7B). So, our data suggest that histone H3 and H4 may have entirely opposing roles in the regulation of KP1019. mediated effects, where $\mathrm{H} 3$ has considerably involved in potentiating while $\mathrm{H} 4$ in neutralizing its effects. The H3 and $\mathrm{H} 4$ residues whose substitutions exhibited phenotype (sensitive/resistant) to KP1019, and that are known for prone to PTMs were represented with a color code and highlighted in the primary sequence of $\mathrm{H} 3$ and $\mathrm{H} 4$ accordingly (Figure 7C). For quantifying the phenotypic response of mutants to KP1019, we allotted the scores numerically from 2 to 4 with positive or negative values as described in methods section subsequent to validation of KP1019 sensitive (Supplementary Figure 15) and resistant mutants (Supplementary Figure 16). For further confirmation, top-scored mutants that exhibited sensitivity and resistance against KP1019 were validated by growth assays (Figure 7D, Supplementary Figure 17A), and growth curve analysis (Supplementary Figure 17B, 17C). Provided that KP1019 destabilizes the nucleosome in vitro and causes DNA damage [24], we attempted to justify the enhanced and decreased effect of KP1019 in sensitive and resistant alleles with regard to aberrant global nucleosome positioning and DNA damage repair pathways, which were assessed by MNase (Micrococcal Nuclease) accessibility assay and Rad53-kinase activation respectively. To our surprise, both the KP1019 sensitive (H3-K18Q) and resistant (H3-K4R) mutants exhibited similar global nucleosome architecture (Supplementary Figure 18A) with proper activation of DNA repair checkpoint Rad53-kinase and induction of ribonucleotide reductases (Rnr1/Rnr2) (Supplementary Figure 18B) compared to wild-type cells upon KP1019 treatment. So, our results indicate the need for further studies to understand the detailed mechanisms and factors responsible for enhancing or decreasing the KP1019 induced cytotoxicity in the histone H3/H4 mutants.

\section{Analysis of structural and functional features of histone $\mathrm{H3} / \mathrm{H} 4$ residues modulating the KP1019- induced cytotoxicity}

To get functional insights of the histone $\mathrm{H} 3 / \mathrm{H} 4$ mutants that displayed differential phenotype to KP1019, we extracted the structural and phenotypic information associated with each of KP1019 sensitive (Supplementary Table 5) and resistant (Supplementary Table 6) histone alleles as annotated in the HistoneHits database [64].
The position of amino acid residues of histones in the nucleosome roughly partitioned into four major geographical domains: buried (protein core that does not exposed to the solvent), disk surface (protein surface that does not contact DNA), lateral (protein surface that contacts DNA), and tail (unstructured in the crystal) [64]. Our detailed analysis of the geographical distribution of histone $\mathrm{H} 3 / \mathrm{H} 4$ residues to nucleosome domains revealed that disk and tail residues are the major contributors for KP1019 sensitivity (Figure 8A) and resistance (Figure 8B). Additionally, the relative comparison of histone $\mathrm{H} 3$ with $\mathrm{H} 4$ mutants indicated that more of lateral and tail residues of histone $\mathrm{H} 3$ significantly contributed to KP1019 sensitivity (Figure 8C), while the disk and lateral residues of histone H4 majorly contributed to KP1019 resistance (Figure 8D). It is also evident that the tails of $\mathrm{H} 3$ and $\mathrm{H} 4$ have antagonistic roles as the loss or gain of PTMs on $\mathrm{H} 3$ tail resulted in sensitive phenotype, whereas $\mathrm{H} 4$ tail showed resistant phenotype to KP1019 (Figure 8C, 8D). Subsequently, the nucleosomal positioning of histone H3 and $\mathrm{H} 4$ residues whose substitution mutation considerably decreased the KP1019 tolerance is illustrated in 3D nucleosome structure (Figure 8E). It further revealed that most of the sensitive $(\mathrm{H} 3 / \mathrm{H} 4)$ residues present on the exposed surface (disk) and primarily involved in DNA wrapping/unwrapping (lateral), and hence critical for transcriptional regulation (Figure 8E).

Furthermore, we attempted to understand the functional roles of $\mathrm{H} 3$ and $\mathrm{H} 4$ residues that conferred phenotype to KP1019 by analyzing the phenotypic data for genetic screens of histone mutants accessible at HistoneHits database. Interestingly, our analysis of functional phenotypes associated with the KP1019 responding mutants emphasized that the mutation of residues involved in ribosomal silencing, telomeric silencing, growth rate, HMR locus silencing, transcription elongation defects, and increased sensitivity to DNA damaging agents (Camptothecin, HU, MMS, UV) conferred sensitivity to KP1019, whereas the mutation of residues involved in ribosomal silencing, telomeric silencing, mating efficiency, H3K56 hyperacetylation, and HMR locus silencing conferred resistance to KP1019 (Figure 8F). The mutants that exhibited phenotype to ribosomal silencing assay and KP1019 might provide correlations between anticancer activity of KP1019 and ribosomal synthesis, which affects cell growth and may increase susceptibility to cancer [65]. Considering the significance of histone point mutations, histone SNPs, along with covalent histone modifications in tumorogenesis and tumor development [66, 67], we attempted to find a relationship between the cancer epigenetic signatures/histone code with the altered KP1019 activity. Amazingly, we found a strong correlation between the human cancer specific histone modification signatures with the enhanced or suppressed effects of KP1019 in corresponding yeast mutants (Figure 8G). 
A)

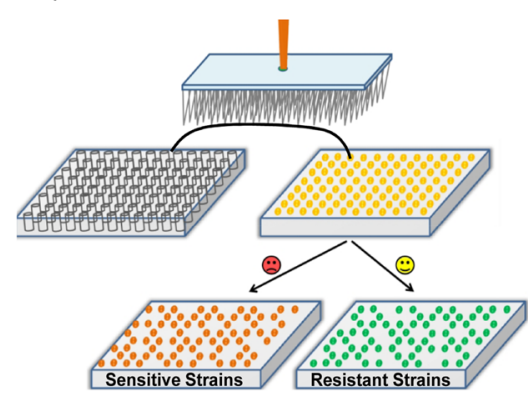

B)

\begin{tabular}{|c|c|c|c|}
\hline & & Sensitive & resistant \\
\hline Total number of H3 Mutants Screened & 249 & & \\
\hline No. of mutants with phenotype & 86 & 64 & 22 \\
\hline$\%$ of total H3 mutants with phenotype & 34.53815 & & \\
\hline$\%$ of total $\mathrm{H} 3$ mutants with sensitive phenotype & 74.4186 & & \\
\hline$\%$ of total H3 mutants with resistant phenotype & 25.5814 & & \\
\hline Total number of H4 Mutants Screened & 172 & & \\
\hline No. of mutants with phenotype & 79 & 19 & 60 \\
\hline$\%$ of total $\mathrm{H} 4$ mutants with phenotype & 45.93 & & \\
\hline$\%$ of total $\mathrm{H} 4$ mutants with sensitive phenotype & 24.05 & & \\
\hline$\%$ of total $\mathrm{H} 4$ mutants with resistant phenotype & 75.95 & & \\
\hline
\end{tabular}

C)

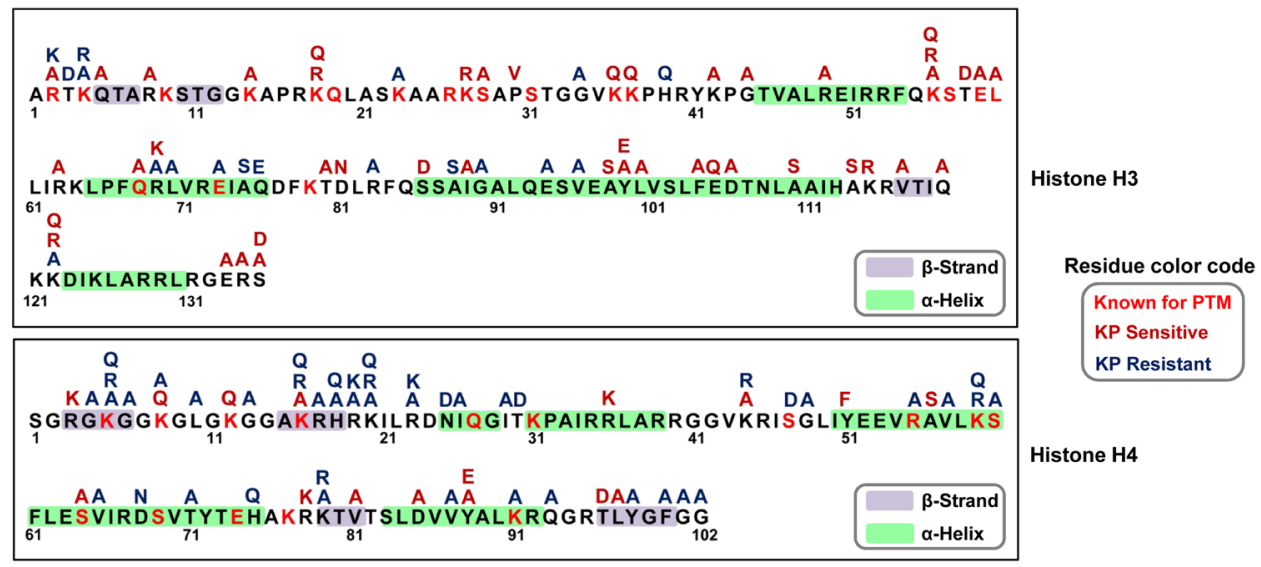

D)
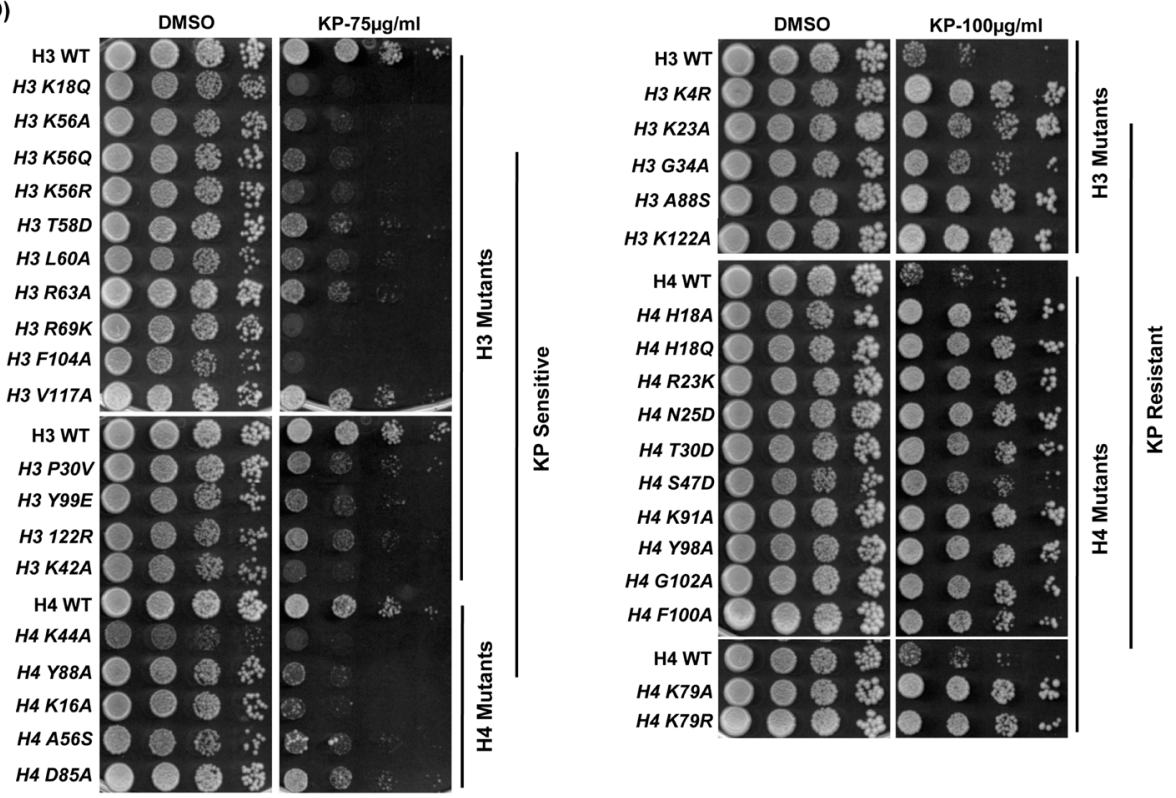

Figure 7: KP1019-induced toxicity is modulated by the mutations, loss or gain of PTMs on histone $\mathrm{H3}$ and $\mathrm{H4}$ residues. (A) Schematic representation of high-throughput methodology adopted for the screening of yeast synthetic histone H3/H4 mutant library to identify the KP1019 sensitive and resistant mutants. The library mutants were grown in 96-well plates and spotted onto SC-agar plates containing different doses of KP1019. (B) Summarization of histone H3/H4 mutant library screening results indicates that KP1019 is highly potent in inducing cytotoxicity in histone $\mathrm{H} 3$ mutants whereas ineffective in histone $\mathrm{H} 4$ mutants. $34.5 \%$ of tested histone $\mathrm{H} 3$ mutants and 45.93\% of tested histone H4 mutants exhibited phenotype (sensitivity/resistance) to KP1019. (C) Substitution mutations indicated above the histone H3, and H4 sequence (yeast) are sensitive (brown) or resistant (blue) to KP1019. The residues that are known for their PTMs (red) and contribution to the secondary structure are indicated within the sequence (based on UniProt database). (D) Validation of topscored mutants those exhibited phenotype to KP1019. Ten-fold serial dilutions of wild-type (WT) and indicated KP1019 sensitive and resistant histone $\mathrm{H} 3 / \mathrm{H} 4$ mutants were spotted onto SC-agar plates supplemented with DMSO or KP1019 (75, 100 $\mu \mathrm{g} / \mathrm{ml})$. The plates were imaged after $48 \mathrm{~h}$. 
A)

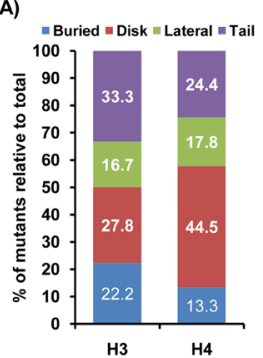

C)

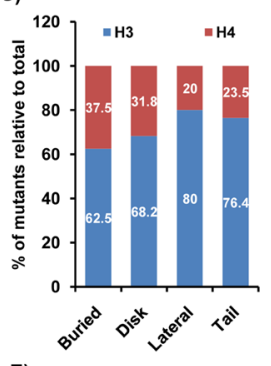

E)

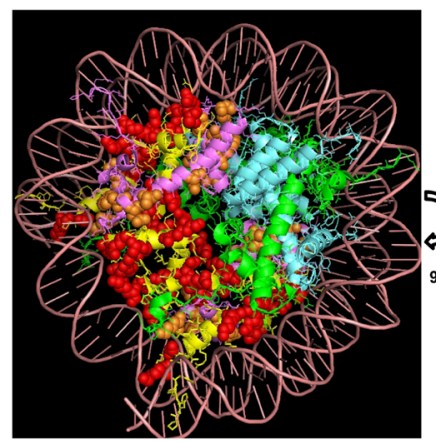

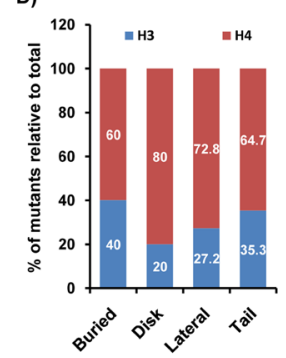

B)

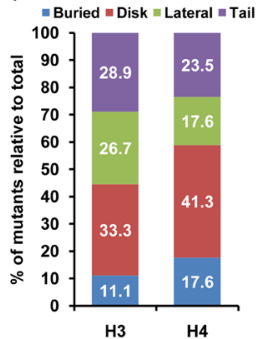

D)
F)

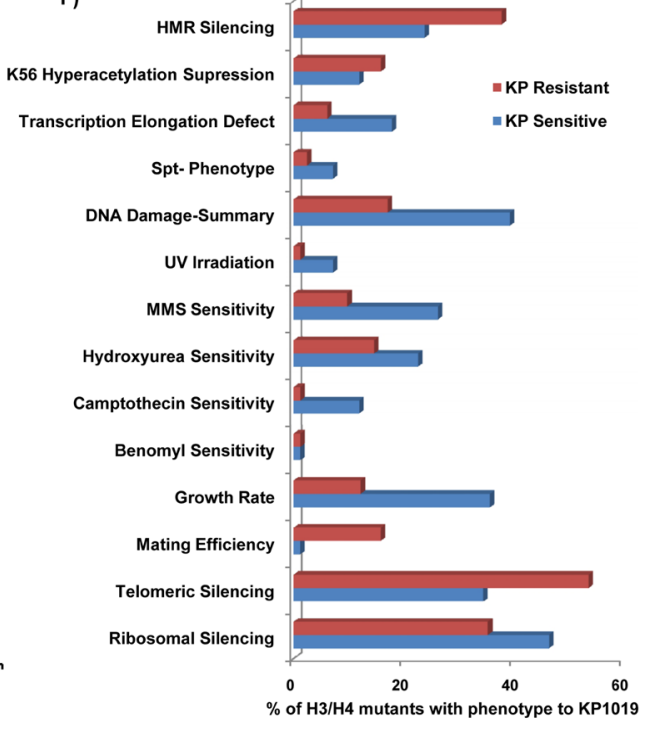

G)
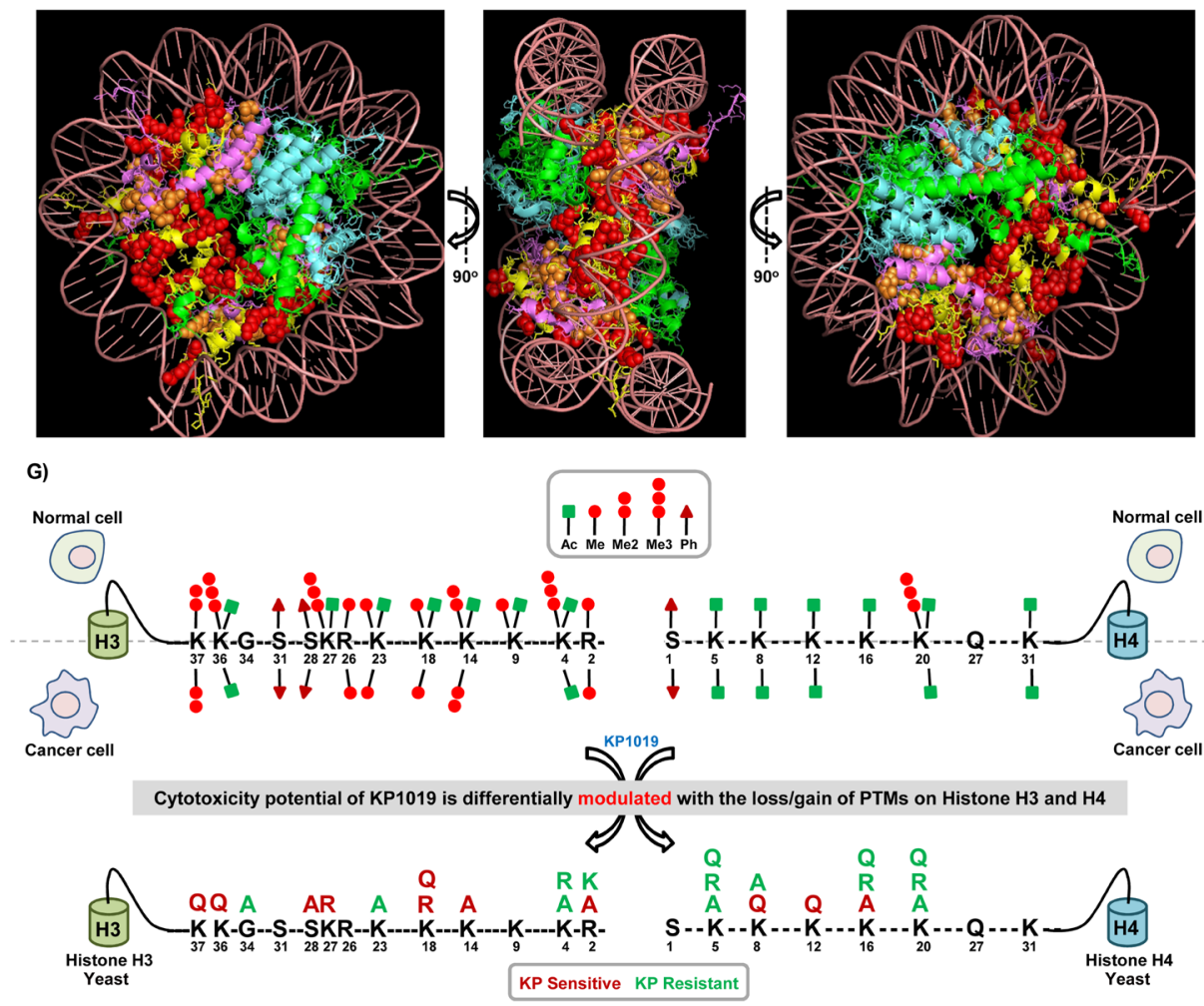

Figure 8: Functional analysis of histone $\mathbf{H 3} / \mathbf{H} 4$ residues that are exhibiting phenotype to KP1019. (A and B) The \% mutants of histone $\mathrm{H} 3$ and $\mathrm{H} 4$ residues positioned in different structural domains of the nucleosome (buried, disk, lateral, and tail) relative to that of the respective total number of mutants exhibited sensitivity (A) or resistance (B) to KP1019. (C and D) The \% distribution of histone $\mathrm{H} 3$ and $\mathrm{H} 4$ mutants based on their residues location in different structural domains of the nucleosome (buried, disk, lateral, and tail) relative to that of the total number of mutants (sum of H3 and H4) exhibited sensitivity (C) or resistance (D) to KP1019. (E) KP1019 sensitive histone $\mathrm{H} 3$ (red) and $\mathrm{H} 4$ (ochre) substitution residues are indicated in the 3D structure of yeast nucleosome (PDB ID: 1ID3). The nucleosome consists of all the four core histones H2A (green), H2B (cyan), H3 (yellow), and H4 (pink), and DNA (maroon) wrapped around the histone core. (F) The histone H3/H4 residues whose substitutions exhibited phenotype to KP1019 have associated with different functional phenotypes. The functional phenotype information for each of residues was extracted from HistoneHits database, and the number of histone $\mathrm{H} 3 / \mathrm{H} 4$ mutants associated with each phenotype was represented as \% relative to that of the total number of KP1019 sensitive and resistant mutants. (G) The toxicity potential of KP1019 is modulated differentially with the loss/gain of PTMs on histone H3/H4 residues. A hallmark of several cancers is the deregulation of PTMs on histone $\mathrm{H} 3$ and $\mathrm{H} 4$ tail residues in cancer cells compared to normal cells. The yeast substitution mutants of those homologous residues have exhibited differential sensitivity to KP1019 and thus suggest the possible influence of histone H3/H4 PTMs signatures on the anticancer potential of KP1019 in mammalian cancer cells. 
Although it is too far to relate our yeast histone mutant phenotypes of KP1019 with human cancer epigenomics and therapeutics, our findings strongly indicate that the cytotoxicity potential of KP1019 might be influenced by the histone substitution mutations and PTMs. Hence, future studies are needed to focus in this direction to elucidate the impact of altered epigenetic modifications on the anticancer potential of KP1019.

\section{DISCUSSION}

In this study, we have elucidated the mode of action of KP1019, a ruthenium-based anticancer drug that has entered phase-II clinical trials after exhibiting successful stabilization of several cancers (colon, endometrium, liver, and tongue) in phase-I trials without any major adverse effects [6]. Our systematic findings in yeast and HeLa cells revealed that the cytotoxic potential of KP1019 could be influenced either by chemical (metals/ reductants/ETA), genetic, or epigenetic factors. We have attempted to understand its off-target effects along with possible approaches to potentiate and neutralize the effects of KP1019. A global transcriptomics approaches such as microarray facilitates to identify the comprehensive set of genes differentially regulated in response to a condition of interest [68]. Transcriptional profiling of KP1019 treated cells exhibited differential regulation of only $5 \%$ of the genome (284 genes induced; 76 genes repressed) specifically. Functional enrichment analysis of KP1019 transcriptome unraveled its probable mode of action and indicated that KP1019 exhibits its effects by affecting several cellular processes such as cell cycle, cellular signaling, DNA damage repair, cell wall biogenesis, metal homeostasis, lipid homeostasis, and ribosomal biogenesis (Figure 1D). Consistent with our KP1019 transcriptome in yeast, recent studies with other ruthenium-based anticancer drugs ( $\mathrm{RDC} 11$ and $\mathrm{RuT}_{7}$ ) in cancer cells also showed functional enrichment of genes belonging to various biological processes including cell cycle, cell morphology, cell signaling, DNA damage repair, protein synthesis, and ribosomal biogenesis [69, 70]. Hence, we propose that the KP1019 transcriptome profile and associated pathways obtained in yeast can be extrapolated to understand the possible conserved mechanisms through which it exerts anticancer activity in cancer cells.

In this study, we found that the activity of KP1019 was drastically decreased by ETA (Figure 4E), $\mathrm{Fe}^{2+}$ (Figure $6 \mathrm{~B}), \mathrm{GSH}$ (Supplementary Figure 11E), and moderately by Sorbitol (Figure 2B). To reason the suppression of KP1019 effects in the presence of various chemical agents (ETA, $\mathrm{Fe}^{2+}, \mathrm{GSH}$, and Sorbitol), we measured the uptake of KP1019 by ICP-MS (Inductively Coupled Plasma Mass Spectrometry) and UV-Vis Spectrometry. Interestingly, our analysis of intracellular accumulation of KP1019 (in terms of Ru levels) by ICP-MS revealed that only GSH significantly reduced its uptake for suppressing the activity, while other agents (ETA, $\mathrm{Fe}^{2+}$, and Sorbitol) do not (Supplementary Figure 19A). The ICP-MS results were supported by UV-Vis estimation of residual KP1019, wherein alteration of its UV-Vis absorption spectrum in the presence of ETA and GSH infers the possible formation of new KP1019 species that is not/less toxic to yeast cells (Supplementary Figure 19B). Our findings indicate the need for further detailed studies to understand both the chemical and functional aspects of KP1019 inactivation by the abovementioned agents.

In budding yeast and mammals, an evolutionarily conserved Ser/Thr protein kinase Target of Rapamycin (TOR) signaling pathway involved in nutrient sensing, is a critical regulator of cell growth as it controls several processes including transcription, translation, and ribosomal biogenesis $[71,72]$. Our results confirm that the TOR pathway is functional in KP1019 treated cells as envisaged by transcriptional induction of ribosomal biogenesis and translational control genes, early nuclear localization of stress- and nutrient-sensitive transcriptional factor Sfp1, phosphorylated Sch9, and functional antagonism of KP1019 with the RAP, an inhibitor of TOR pathway (Figure 5). Since TOR signaling activity is known to negatively regulate the Pkc1 kinase of CWI pathway that regulates functions related to cell growth and integrity under nutrient rich conditions [73], our failure to observe the activation of MAP kinase Mpk1 (p44/42) upon KP1019 treatment in yeast cells (Figure 2C) could be credited to the functional TOR pathway (Figure 5). It is worth noted that the anticancer activity of KP1339 (a sodium salt of KP1019) was significantly enhanced by co-administering it with Sorafenib, one of the multitargeted tyrosine kinase inhibitors [74]. The deregulation of cell growth and cellular signaling including TOR pathway are not only implicated in tumor development, but also in drug resistance against chemotherapy [75]. Hence, the inhibitors of TOR pathway including RAP have underscored as anticancer drugs in addition to their immunosuppressant activity [76]. Despite the conservation of TOR pathway from yeast to mammals, the functional antagonism that was observed between RAP and KP1019 in yeast cells (Figure 5D) could not be mimicked in HeLa cell lines in vitro (Figure 5E). Hence, our results do not encourage further studies aimed at elucidating the therapeutic outcome of KP1019 in combination with RAP.

Besides acting as a TOR pathway inhibitor, RAP along with other macrocyclic lactones (Ivermectin, cyclosporine) were shown to potentially inhibit the function of SERCA pumps, thus alters $\mathrm{Ca}^{2+}$ ion homeostasis [77]. Interestingly, recent study has shown that KP1019 also inhibit SERCA and interfere with ATP-dependent $\mathrm{Ca}^{2+}$ translocation in vitro [37]. We demonstrate here in vivo that Pmr1, a $\mathrm{Ca}^{2+} / \mathrm{Mn}^{2+}$ P-type ATPase involved in the transport of $\mathrm{Ca}^{2+}$ and $\mathrm{Mn}^{2+}$ ions to Golgi, is essential for KP1019 tolerance (Figure 3A). Given that Pmr1-dependent transport of $\mathrm{Mn}^{2+}$ ions to 
Golgi is essential for RAP sensitivity [78], we attribute the functional antagonism observed between anticancer drugs RAP and KP1019 in yeast cells to their competitive antagonistic interaction with different P-type ATPase enzymes $\left(\mathrm{Na}^{+} / \mathrm{K}^{+}, \mathrm{H}^{+} / \mathrm{K}^{+}\right.$, and $\left.\mathrm{Ca}^{2+} / \mathrm{H}^{+}\right)$directly or indirectly (Figure 5D). Given this hypothesis, it will be noteworthy to propose the use of KP1019 in combination with SERCA/P-type ATPase inhibitors, emerging anticancer drugs for achieving the synergetic therapeutic effect against multidrug-resistant tumors [79, 80].

P-type ATPases selectively catalyze the active transport of essential ions like $\mathrm{H}^{+}, \mathrm{K}^{+}, \mathrm{Mn}^{2+}, \mathrm{Na}^{+}, \mathrm{Ca}^{2+}$, $\mathrm{Co}^{2+}, \mathrm{Cu}^{2+}$, and $\mathrm{Zn}^{2+}$ to maintain proper gradients across diverse cellular membranes [79]. These trace metal ions are essential for the functioning of various metalloenzymes and are toxic at higher concentration. The tight regulation of ions involved in multifunctional signaling is vital for cellular survival. The derivatives of metal ions are implied nowadays as therapeutic drugs such as antibacterial, antifungal, and anticancer agents [81]. Given that KP1019 interfere with SERCA/P-type ATPase mediated $\mathrm{Ca}^{2+}$ translocation in vitro [37], we speculated that KP1019 can alter intracellular metal ion homeostasis. Consequently, our results demonstrated that the cytotoxicity potential of KP1019 is augmented in combination with $\mathrm{Al}^{3+}, \mathrm{Ca}^{2+}$, $\mathrm{Cd}^{2+}, \mathrm{Cu}^{2+}, \mathrm{Mn}^{2+}, \mathrm{Na}^{+}$, and $\mathrm{Zn}^{2+}$ ions (Figure 6). Since many heavy metal ions $\left(\mathrm{Cd}^{2+}, \mathrm{Cu}^{2+}\right.$, and $\left.\mathrm{Zn}^{2+}\right)$ have the ability to affect the activity of P-type ATPase $\left(\mathrm{Mg}^{2+} / \mathrm{Na}^{+}\right.$, $\mathrm{K}^{+} / \mathrm{Ca}^{2+}$ ) similar to KP1019 [82], the obtained synergetic toxicity of KP1019 with various metal ions is possibly due to altered homeostasis and/or increased metal ion load in combination. Besides, the affinity of transferrin to transport other metal ions $\left(\mathrm{Al}^{3+}, \mathrm{Ni}^{2+}, \mathrm{Mn}^{2+}, \mathrm{Cr}^{3+}, \mathrm{Bi}^{3+}\right.$, $\left.\mathrm{Ru}^{3+}, \mathrm{Ti}^{4+}, \mathrm{V}^{4+}\right)$ in addition to $\mathrm{Fe}^{3+}[83,84]$, and altered ability of KP1019 to bind with apo-transferrin loaded with other metal ions are expected to affect KP1019 uptake and hence its activity. Strikingly, Farah et al. reported that the concentrations and metal load of major elements $(\mathrm{Al} /$ $\mathrm{Ba} / \mathrm{Ca} / \mathrm{Cr} / \mathrm{Cu} / \mathrm{Fe} / \mathrm{Mg} / \mathrm{Na} / \mathrm{Pb} / \mathrm{Se} / \mathrm{Sr} / \mathrm{Zn}$ ) were significantly higher in tumor tissues compared to normal tissues of human lung, breast, and liver [85]. To add to the earlier proposed tumor specific transferrin-mediated uptake and redox activation of KP1019, we show that higher metal loads or altered ion homeostasis in tumor also selectively exaggerates KP1019 activity in cancerous cells compared to normal healthy cells.

One of the major hallmarks of a cancer cell is their ability to undergo metabolic reprogramming from respiration to aerobic glycolysis (known as the Warburg effect) [86], for fulfilling the demands of rapidly proliferating cells. It does so either by increasing the uptake of exogenous lipids (dietary) or overactivating the de novo lipogenesis to continuously provide cholesterol and fatty acids (FAs) required for cell membrane synthesis, cell cycle progression, cytokinesis, and energy supply $[87,88]$. The physiology and metabolic fluxes of cancer cells are similar to that of fermenting yeast cells and most of the lipids metabolizing enzymes critical for cancer cell proliferation are conserved in $S$. cerevisiae [48]. Excessive FAs, lipids, and cholesterol are stored in the form of LDs in almost all eukaryotic cells and higher LDs and stored-cholesteryl ester content in tumors are ascribed as hallmarks of cancer aggressiveness [89]. The recent chemotherapeutics have thus been designed to attenuate the proliferation of cancer cells through manipulating FAs synthesis, metabolism, and diminishing the FAs availability [88]. We demonstrate here that genes involved in lipid homeostasis are critical for KP1019 tolerance (Figure 3E). Furthermore, we show that KP1019 treatment leads to accumulation of LDs in both yeast (Figure 3F, 3G) and mammalian HeLa cells (Figure 4A, 4B). Hence, we speculate that KP1019 inhibits the synthesis of phospholipids (PE; PC) by interfering with FAs utilization. This in turn promotes accumulation of LDs to inhibit the proliferation and induce apoptosis of cancer cells. This is further exemplified by the fact that the effects of KP1019 were remediated in the presence of ETA (Figure 4D, 4E), a precursor utilized by the Kennedy pathway for de novo synthesis of phospholipids [51]. From the physiological point of view, the accumulation of LDs occurs when cells are either maintained in medium containing excess FAs/ lipoproteins or exposed to stress stimuli leading to cell death [90-92]. Hence, LDs accumulation is considered as a hallmark of apoptosis [93], and this phenomenon is observed in different metabolic diseases [94, 95], induced by various forms of stress stimuli including mitochondrial dysfunction and oxidative stress [93, 96], ER stress [97, 98], osmotic stress [99], inhibition of MYC in cancer cells [100], and activation of TOR pathway [101]. Though our results strongly suggest that KP1019 alters lipid metabolism and induces LDs accumulation, the molecular mechanisms behind its effects are yet to be answered.

Although LDs arise typically from ER and reside in the cytoplasm, emerging evidence suggests that LDs could sequester enzymes, transcription factors, and chromatin components to control their availability in the nucleus [102]. Conversely, several anticancer and epigenetic drugs such as cisplatin, 5-Azacytidine, YC-1, and Entinostat effectively interfered with lipid metabolism to stimulate LDs accumulation [103-106]. The question, then is whether LDs accumulation as a cause or consequence of KP1019 effects on epigenetic events. Although the major target of KP1019 in eukaryotic cells is found to be DNA, our earlier findings showed that KP1019 forms adduct with histone $\mathrm{H} 3$ and evicts histones from nucleosome in vitro. The essentiality of histones and chromatin modifiers for KP1019 tolerance specify that it mediate its effects by modulating epigenetic events [24]. To assess how mutations and/or loss/gain of PTMs on histones H3/H4 modulate KP1019-mediated signaling and impact its effectiveness, we utilized yeast synthetic histone H3/H4 mutant library for functional screening 

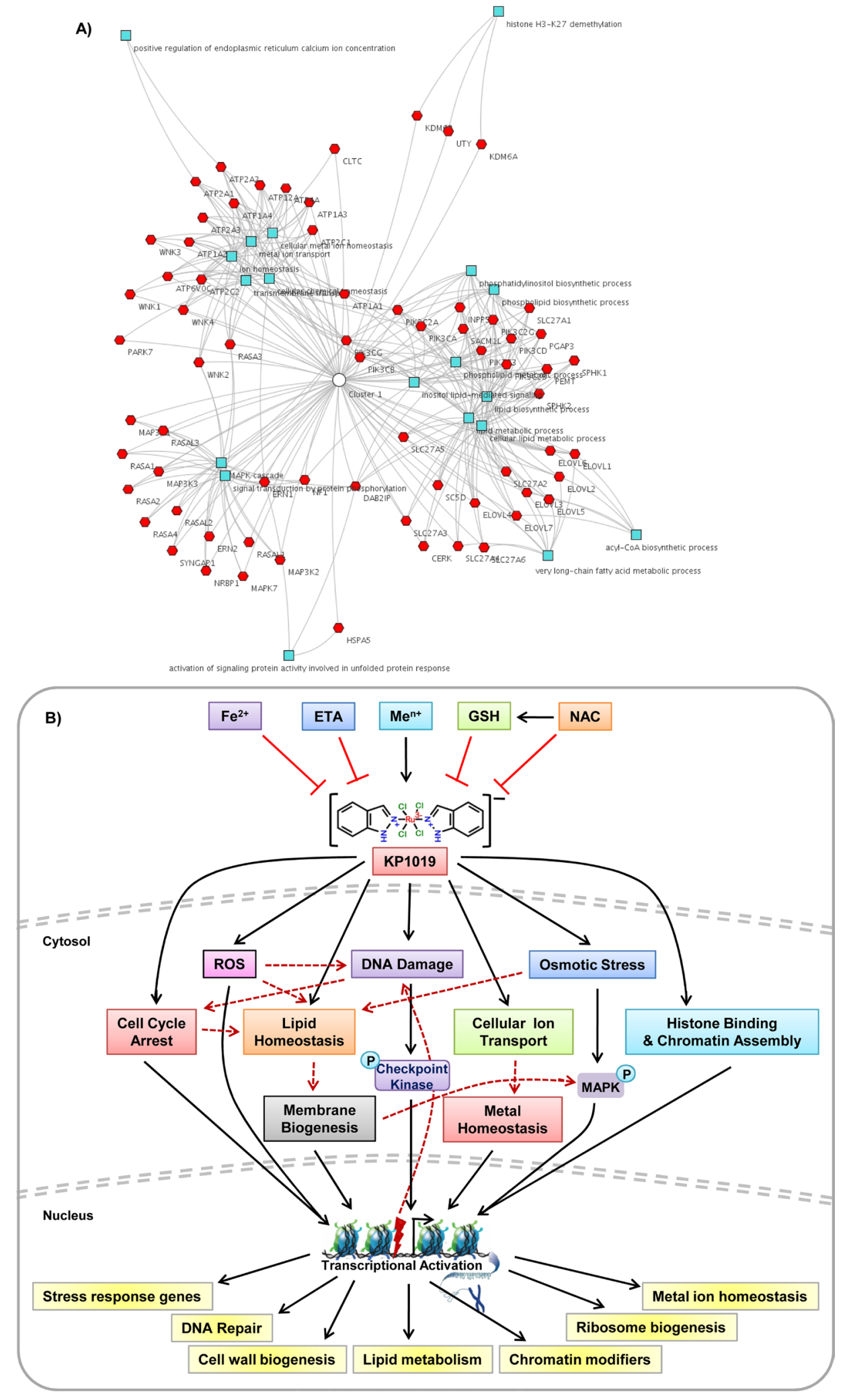

Figure 9: A proposed model depicting the mode of action of KP1019. (A) Functional classification of human homologous genes targeted by KP1019 in yeast using ToppCluster tool. (B) Model illustrating the mode of action of KP1019. Biologically active KP1019 induces ROS generation, causes DNA damage and thus cell cycle arrest, activates MAP kinase signaling, alters intracellular metal ion and lipid homeostasis, and also affects the chromatin assembly. The cells activate transcriptional response to alleviate KP1019 induced cellular damage. Moreover, the toxicity potential of KP1019 is enhanced in the presence of various metal ions $\left(\mathrm{Me}^{\mathrm{n}+}\right)$, whereas suppressed by the supplementation of $\mathrm{Fe}^{2+}$ ions, reduced glutathione (GSH), N-acetylcysteine (NAC), and ethanolamine (ETA). 
Table 1: Identification of human homologs of yeast genes (that are required for KP1019 tolerance) and their functional role in the implication of various diseases using YeastMine tool

\begin{tabular}{|c|c|c|c|}
\hline S.No. & Yeast KP target Gene & Human Homolog & OMIM Disease \\
\hline 1 & BCK1 & $\begin{array}{c}\text { MAP3K } 1 / 2 / 3, \text { NRBP } 1 / 2, \\
\text { WNK } 1 / 2 / 3 / 4\end{array}$ & $\begin{array}{c}\text { SRXY6, PHA2B, PHA2C, } \\
\text { HSAN2A }\end{array}$ \\
\hline 2 & $\mathrm{CHC} 1$ & CLTC, CLTCL1 & \\
\hline 3 & $\mathrm{CYC} 8$ & KDM6A/B, UTY & Kabuki Syndrome 2 \\
\hline 4 & ELO3 & ELOVL1/2/3/4/5/6/7 & $\begin{array}{c}\text { ISQMR, SCA34, STGD3, } \\
\text { SCA38 }\end{array}$ \\
\hline 5 & ERG6 & COQ3, WBSCR27 & \\
\hline 6 & FAT1 & SLC27A1/2/3/4/5/6 & $\begin{array}{l}\text { Ichthyosis Prematurity } \\
\text { Syndrome }\end{array}$ \\
\hline 7 & GUP1 & HHAT, HHATL & \\
\hline 8 & IRA2 & $\begin{array}{l}\text { DAB2IP, NF1, RASA1/2/3/4, } \\
\text { RASAL1/2/3, SYNGAP1 }\end{array}$ & $\begin{array}{c}\text { NF1, JMML, WTSN, NFNS, } \\
\text { BCC1, Parkes Weber Syndrome, } \\
\text { MRD5 }\end{array}$ \\
\hline 9 & IRE1 & ERN1/2 & \\
\hline 10 & LCB5 & CERK, CERKL, SPHK1/2 & Retinitis Pigmentosa 26 \\
\hline 11 & OPI3 & PEMT & \\
\hline 12 & PER1 & PGAP3 & HPMRS4 \\
\hline 13 & PMR1 & $\begin{array}{l}\text { ATP1A1/2/3/4, ATP2A1/2/3, } \\
\text { ATP2C1/2, ATP4A, ATP12A }\end{array}$ & $\begin{array}{c}\text { FHM2, AHC1, AHC2, Dystonia } \\
\text { 12, CAPOS, Brody Myopathy, } \\
\text { Darier-White Disease, AKV, } \\
\text { BCPM }\end{array}$ \\
\hline 14 & PRE9 & PSMA4 & \\
\hline 15 & RPS27B & RPS27, RPS27L & \\
\hline 16 & SAC1 & INPP5F, SACM1L & \\
\hline 17 & SLT2 & MAPK7 & \\
\hline 18 & TUP1 & ELP2 & \\
\hline 19 & VMA3 & ATP6V0C & \\
\hline 20 & VPS16 & VPS16 & \\
\hline 21 & VPS34 & $\begin{array}{c}\mathrm{PIK} 3 \mathrm{C} 2 \mathrm{~A} / \mathrm{B} / \mathrm{G}, \mathrm{PIK} 3 \mathrm{C} 3, \\
\mathrm{PIK} 3 \mathrm{CA} / \mathrm{B} / \mathrm{D} / \mathrm{G}\end{array}$ & $\begin{array}{l}\text { Breast Cancer, Colorectal } \\
\text { Cancer, CWS5, Gastric Cancer, } \\
\text { Hepatocellular Carcinoma, } \\
\text { IMD14, Keratosis, LCACC, } \\
\text { MCAP, Nevus, Ovarian Cancer }\end{array}$ \\
\hline 22 & VRP1 & WIPF $1 / 2 / 3$ & Wiskott-Aldrich Syndrome 2 \\
\hline 23 & YTA7 & ATAD2, ATAD2B & \\
\hline
\end{tabular}

SRXY6, XY Sex Reversal 6; PHA2C, Pseudohypoaldosteronism, Type IIC; PHA2B, Pseudohypoaldosteronism, Type IIB; HSAN2A, Neuropathy, Hereditary Sensory and Autonomic, Type IIA; ISQMR, Ichthyosis, Spastic Quadriplegia, and Mental Retardation; SCA34, Spinocerebellar Ataxia 34; STGD3, Stargardt Disease 3; SCA38, Spinocerebellar Ataxia 38; NF1, Neurofibromatosis, Type I; JMML, Juvenile Myelomonocytic Leukemia; WTSN, Watson Syndrome; NFNS, Neurofibromatosis-Noonan Syndrome; BCC1, Basal Cell Carcinoma, Susceptibility to, 1; MRD5, Mental Retardation, Autosomal Dominant 5; HPMRS4, Hyperphosphatasia With Mental Retardation Syndrome 4; MIGRAINE, FHM2, Familial Hemiplegic, 2; AHC1/AHC2, Alternating Hemiplegia of Childhood 1/2; CAPOS, Cerebellar Ataxia, Areflexia, Pes Cavus, Optic Atrophy, and Sensorineural Hearing Loss; AKV, Acrokeratosis Verruciformis; BCPM, Benign Chronic Pemphigus; CWS5, Cowden Syndrome 5; IMD14, Immunodeficiency 14; LCACC, Lung Cancer Alveolar Cell Carcinoma; MCAP, Megalencephaly-Capillary Malformation-Polymicrogyria Syndrome. 
with KP1019. Remarkably, our results demonstrated that KP1019 effects were majorly mediated through histone H3-dependant functions and neutralized by the histone H4-mediated functions (Figure 7B). These contrasting effects of KP1019 on H3 and H4 might be credited to the opposing roles of $\mathrm{H} 3$ and H4 PTMs in regulating nucleosome structure [107]. Moreover, the loss/gain of PTMs and histone code on tails tightly regulate the higher-order chromatin architecture by affecting histoneDNA interaction and thus nucleosome stability [108]. Because the histones in yeast are highly conserved and many residues are modified at the same sites as those found in higher eukaryotes, we attempted to correlate the differential activity of KP1019 observed with histone H3/ H4 mutants to epigenetic signatures in different cancers and cell types. For instance, almost all types of cancers exhibited global loss of acetylation (Ac) at Lys16 and trimethylation (Me3) at Lys20 of histone H4 [109], and substitution mutations in these residues neutralized KP1019 effects in yeast, thus accrediting the possible role of these PTMs to cancer selective cytotoxicity of KP1019 (Figure 8G). Besides, the point mutations in histones [110], along with loss/gain of PTMs on Lys4, Lys9, Ser10, Lys14, Lys18, Lys23, Lys27, Gly34, and Lys36 of histone $\mathrm{H} 3$ have been linked to tumorogenesis and cancer progression [111-113], and the mutations on these residues influenced KP1019 effects positively/ negatively in yeast cells (Figure 8G). Previously, Sharma et al. have observed that cancer cells employ chromatinmediated dynamic survival strategies by presuming a reversible drug-tolerant state to eradicate the anticancer drugs [114]. Therefore, our findings with the functional screening of histone H3/H4 library against KP1019 may provide information about the critical residues and histone code that guide the cytotoxicity of KP1019 selectively to cancer cells and only to certain cell types. Further studies are needed to decipher how these substitution mutations on histone $\mathrm{H} 3 / \mathrm{H} 4$ affect the nucleosome architecture and bring genome-wide alterations in the transcriptome. This will provide clues about the critical epigenetic processes that are involved in manipulating the therapeutic potential of KP1019.

The genetic targets of KP1019 identified here in yeast through chemical-genetics approach were shown in Table 1, and they are found to have multiple counterparts (homologs) in humans implicated in the progression of various cancers, neurological, immunological disorders and diseases (Table 1). We, however couldn't find any of the KP1019 targets to match with that of platinumbased anticancer drug Cisplatin except that of DNA repair [115]. We, thus propose that KP1019 mode of action is different from Cisplatin and can be used in combination for cancer treatment. The functional interactions existing among the human homologs of KP1019 target genes also indicated the similar biological processes that were found in yeast, including metal ion homeostasis, lipid/ fatty acid biosynthesis and metabolism, MAPK signaling cascade, UPR, and histone modifiers (Figure 9A). Hence, our findings reveal the importance of unicellular budding yeast in assessing the mode of action of biologically active molecules including anticancer drugs. As budding yeast shares conserved basic cellular processes including metabolic and signaling mechanisms linked to cancer, we speculate that this study findings in yeast and mammalian HeLa cells will facilitate the understanding of diverse cellular targets of KP1019 and mechanisms of its anticancer activity in more complex higher eukaryotes such as humans [116].

In summary, we proposed a comprehensive model depicting the mode of action and cellular pathways targeted by KP1019 (Figure 9B). The toxic effects of KP1019 were positively influenced by various metal ions $\left(\mathrm{Me}^{\mathrm{n}+}\right)$, whereas negatively regulated by ETA, $\mathrm{Fe}^{2+}$, and reducing agents (GSH/NAC). KP1019 mediate its toxic effects through cell cycle arrest, DNA damage, oxidative stress, osmotic stress, by altering cellular signaling, metal homeostasis, transport, and lipid homeostasis. We also demonstrate that the efficiency of KP1019 and its effects are dependent on epigenetic signatures and histone code. Altogether, our detailed transcriptomics analysis and genetic targets identified in this study shed light on several cellular processes targeted by KP1019, and aid in understanding the molecular mode of action of this clinically important anticancer drug, and perhaps also its sodium salt (KP1339) that is undergoing clinical trials.

\section{MATERIALS AND METHODS}

\section{Synthesis of KP1019}

The anticancer ruthenium complex KP1019 was synthesized according to the established method [117]. $\mathrm{RuCl}_{3} \cdot 3 \mathrm{H}_{2} \mathrm{O}$ was purchased from Sisco Research Laboratories Pvt. Ltd. (India), and indazole was obtained from Sigma-Aldrich (India). The solvents used in the synthesis were procured from Merck (India). The identity of KP1019 was confirmed using electrospray ionisation mass spectrometry (ESI-MS) coupled with liquid chromatography (LC-MS), and UV-Vis spectroscopy (Supplementary Figure 10). The ESI mass spectrum of KP1019 was found similar to that of our earlier observation [24] and other's report [60].

\section{Cell culture conditions, cell morphology, and cytotoxicity assay}

HeLa cells were procured from ATCC (Manassas, VA, USA) and cultured in standard Dulbecco's Modified Eagles' Medium (DMEM) supplemented with 10\% heat-inactivated fetal bovine serum (FBS), 1X solution of antibiotic-antimycotic (Thermo Fisher, India) and maintained at $37^{\circ} \mathrm{C}$ in a humidified atmosphere 
containing $5 \%(\mathrm{v} / \mathrm{v}) \mathrm{CO}_{2}$. For testing the cytotoxicity (antiproliferative) potential of KP1019, Rapamycin (RAP), and metal cation chlorides $\left(\mathrm{Al}^{3+}, \mathrm{Ca}^{2+}, \mathrm{Cd}^{2+}\right.$, $\mathrm{Co}^{2+}, \mathrm{Cu}^{2+}, \mathrm{Fe}^{2+}, \mathrm{Mg}^{2+}, \mathrm{Mn}^{2+}, \mathrm{Na}^{+}, \mathrm{Ni}^{2+}$, and $\mathrm{Zn}^{2+}$ ) in alone or combination, we performed standard MTT [3-(4,5-dimethylthiazol-2-yl)-2,5diphenyltetrazolium bromide] cell viability assay as described earlier [118]. Briefly, HeLa cells were seeded in a 96-well plate at a density of 7000 cells/well and left undisturbed for $24 \mathrm{~h}$. The stock solutions of KP1019 and RAP were prepared in DMSO, whereas metal chlorides in distilled water. The doses of KP1019, RAP and metal chlorides at which $85 \%$ of the cells will be viable upon individual treatment, were selected and added in duplicate to the 96-well plate in alone or combination. After $36 \mathrm{~h}$ of incubation, the medium was replaced with an equal volume of fresh DMEM containing a final $0.2 \mathrm{mg} / \mathrm{ml}$ of MTT reagent (Calbiochem, India) and incubated for $4 \mathrm{~h}$. The resultant formazan crystals were dissolved in DMSO solvent and the absorbance values were recorded at 570 and $690 \mathrm{~nm}$.

The viability of cells was calculated as $\%$ of control as following: $\%$ of control $=\left[\left(\mathrm{OD}_{\mathrm{t}}-\mathrm{OD}_{\mathrm{b}}\right) /\left(\mathrm{OD}_{\mathrm{c}}-\mathrm{OD}_{\mathrm{b}}\right)\right]^{*} 100$. ' $\mathrm{OD}_{t}$ ' represents the mean absorbance of treated cells at $570 \mathrm{~nm}$, 'OD' represents the mean absorbance of solvent (DMSO) treated control cells at 570nm, and ' $\mathrm{OD}_{\mathrm{b}}$ ' represents the mean absorbance of respective well at $690 \mathrm{~nm}$. Additionally, the abovementioned treatments were repeated in a $24-w e l l$ plate $(40,000$ cells/well). After 36h, the morphology of HeLa cells was recorded using an inverted microscope (Axio Vert.A1; Zeiss).

\section{Strains, chemicals, growth media, and growth conditions}

The Saccharomyces cerevisiae strains used in this study were listed in Supplementary Table 1. Both the yeast knockout (YKO) collection and histone $\mathrm{H} 3 / \mathrm{H} 4$ library derived by Dai et al. [63] were purchased from Open Biosystems. Unless stated otherwise, all yeast strains used in this study were grown at $30^{\circ} \mathrm{C}$ in standard synthetic complete (SC) liquid media containing $2 \%$ glucose. SC liquid media was prepared by mixing all amino acids, yeast nitrogen base (YNB) and ammonium sulfate (AS) together by following a standard protocol (Yeast Protocols Handbook, Clontech laboratories, Inc.). The wild-type yeast cells were transformed with pPW344 (URA3), pHL126 (URA3) plasmids using the standard lithium acetate procedure [119] and the resultant transformants were propagated in SC (Uracil dropped) liquid media. For solid agar media, 2\% Bacto-agar was used in addition to SC media components. Media components and all other reagents used in this study were of molecular biology grade and purchased from Sigma-Aldrich, Merck, Himedia, GE Healthcare, Invitrogen, New England BioLabs and Thermo Fisher Scientific. Some of the metal chlorides were from Rankem, India.

\section{Growth sensitivity and growth curve assays}

Growth sensitivity assay was performed to examine the effect of KP1019 on the growth of yeast cells as described previously [120]. In brief, overnight cultures of wild-type (WT) and mutant yeast cells were ten-fold serially diluted and $3 \mu \mathrm{l}$ of each was spotted onto solid SCagar plates without (DMSO control) or with addition of KP1019, ethanolamine (ETA), rapamycin (RAP), sorbitol, reduced glutathione (GSH), N-acetylcysteine (NAC), and metal cation chlorides alone or in combination at indicated doses. All the plates were incubated at $30^{\circ} \mathrm{C}$ and growth was recorded after $72 \mathrm{~h}$ using HP scanner.

For growth curve analysis, exponentially growing yeast cells were treated in duplicate with either DMSO (control) or indicated doses of KP1019, ETA, and GSH alone or in combination and then seeded in a 96-well cell culture plate (SPL Life Sciences Ltd.). Growth curves were constructed for each treatment using representative optical density $\left(\mathrm{OD}_{600}\right)$ values measured at a regular interval of $30 \mathrm{~min}$ for indicated period using a plate reader (Eon ${ }^{\mathrm{TM}}$ Microplate Spectrophotometer) [121].

\section{Total RNA isolation and global transcriptome analysis}

The exponentially growing wild-type yeast $(1588-4 \mathrm{C})$ cells were treated with $\mathrm{KP} 1019(50 \mu \mathrm{g} / \mathrm{ml})$ or equivalent DMSO (solvent control) for $3 \mathrm{~h}$ and then harvested. Total RNAs were isolated by heat/freeze Phenol method as described earlier [122] and assessed its integrity and quality by Agilent 2100 Bioanalyzer (Agilent Technologies, CA) prior to proceeding for gene expression profiling using Affymetrix microarray platform at iLife Discoveries (Gurgaon, India) [121]. Briefly, biotinylated complementary RNA (cRNA) was prepared from $6 \mu \mathrm{g}$ of total RNA from two independent biological repeats of each DMSO and KP1019 treated cells using in vitro transcription reaction and then hybridized to Yeast Genome 2.0 GeneChip Arrays (GPL2529) by following a standard Affymetrix protocol. Afterward, GeneChips were washed, stained in the Fluidics Station 450 (Affymetrix) and scanned using the GeneArray 30007G microarray scanner. The data sets were extracted from all CEL (raw intensity) files and submitted to NCBI's Gene Expression Omnibus (GEO) repository with a GEO Series accession number of GSE76985 (https:/www.ncbi.nlm.nih.gov/geo/ query/acc.cgi?acc=GSE76985).

The raw signals (CEL) in each array were processed for background adjustment, normalization followed by log transformation and summarization of probe sets using RMA (Robust Multi-array Average) algorithm in GeneSpring GX 12.6 expression analysis software (Agilent Technologies, CA). Differentially expressed genes (DEG's) whose expression altered (induced or repressed) significantly by 1.5 -fold $(>1.5)$ in KP1019 treatment compared to 
DMSO (control) were determined by moderated t-test $(p<0.05)$. Functional classification and Gene Ontology (GO) enrichment analysis of DEG's were performed using standard tools described in the supplementary information.

\section{Reverse transcriptase-pcr (RT-PCR)}

Total cellular RNAs were extracted from yeast cells by heat/freeze phenol method as described earlier [122]. $1 \mu \mathrm{g}$ of DNA-free RNA was reverse transcribed to cDNA as per method supplied by iScript cDNA Synthesis Kit (Bio-Rad, India). The cDNA was amplified by PCR using Taq DNA Polymerase, reverse and forward primers of HAC1-S (F: 5'-TAGAGGGATTTCCAGAGCACG-3'; R: 5'-TCATTGAAGTGATGAAGAAATC-3') and ACT1 (F: 5'-CACCCTGTTCTTTTGACTGAAGC-3'; R: 5'-TACCGGCAGATTCCAAACCC-3'). The PCR amplicon products were electrophoresed, stained with ethidium bromide, and photographed [123].

\section{Preparation of protein extracts and immunoblotting analysis}

Whole-cell protein extracts were obtained by $20 \%$ Trichloroacetic acid (TCA) precipitation method as described previously [124]. The protein extracts were resolved by electrophoresis on a SDS-polyacrylamide gel and transferred to nitrocellulose membranes. Immunoblotting analysis was performed by following a standard protocol. Briefly, the nitrocellulose membranes were blocked for $45 \mathrm{~min}$ using blocking buffer $(2.5 \%$ Bovine serum albumin in TBST; TBS containing $0.05 \%$ Tween-20) followed by incubation with primary antibodies for $90 \mathrm{~min}$ (overnight for $\alpha-\mathrm{S} 758-\mathrm{P}$ at $4^{\circ} \mathrm{C}$ ). After washing with TBST, the membranes were incubated with relevant secondary antibody such as IRDye $800 \mathrm{CW}$ Goat anti-Rabbit IgG or anti-Mouse IgG (1:15000, LI-COR Biosciences) for $45 \mathrm{~min}$. Following primary antibodies were used: Anti-Rnr1 (Agrisera, ASO9576), Anti-Rnr2 (Agrisera, ASO9 575), Anti-Sml1 (Agrisera, AS10847), Anti-Rad53 (Santa Cruz Biotechnology Inc., SC-6749), Anti-Mpk1 (Santa Cruz Biotechnology Inc., SC-6803), and Anti-Phospho-p44/42 MAPK antibody (Cell Signaling, 4370). Anti-S758-P (Sch9-P) antibody was a kind gift from Prof. Robbie J. Loewith (University of Geneva, Switzerland). Polyclonal antibodies against recombinant Tbp and Rap1 were raised in rabbit. Blots were scanned by using Odyssey infrared imager (LI-COR Biosciences). Anti-Rad53 western signals were detected by chemiluminescence using Fuji gel-dock system (LAS-4000 mini).

\section{$\beta$-galactosidase activity assay}

The $\beta$-galactosidase assay was performed to monitor the expression levels of UPRE-lacZ reporter gene as described previously [125]. Briefly, the exponentially growing wild-type (BY4741) yeast cells $\left(\mathrm{OD}_{600}: 0.8-1\right)$ carrying $2 \mu$ UPRE-lacZ reporter plasmid ( $p P W 344$; gifted by Laran T. Jensen) [126] were treated with either DMSO (solvent control) or indicated doses of KP1019 (50, $100 \mu \mathrm{g} /$ $\mathrm{ml} ; 3 \mathrm{~h})$ and tunicamycin $(1 \mu \mathrm{g} / \mathrm{ml} ; 1 \mathrm{~h})$ in SC (Ura dropped) media. Prior to harvesting the cells, the cell density at $\mathrm{OD}_{600}$ was determined. The $\beta$-galactosidase activity was measured by permeabilizing the cells in $1 \mathrm{ml}$ of $\mathrm{Z}$ buffer and using ONPG (ortho-Nitrophenyl- $\beta$-D-galactoside; $4 \mathrm{mg} / \mathrm{ml}$ ) as a substrate. The galactosidase activity was expressed in terms of Miller units as described earlier [127].

\section{Lipid droplets (LDs) visualization and ApoTome microscopy}

To investigate the effects of KP1019 on neutral lipids (LDs), ER architecture, and Sfp1 localization in yeast, we employed BODIPY 493/503 dye [128], cells harbouring ss-dsRed-HDEL reporter (GSHY583; stains cortical and nuclear ER) [46], and pHL126 plasmid (pRS416-GFP-SFP1; gifted by David Shore) [129], respectively. Exponentially growing yeast cells were left untreated (DMSO control) or treated with KP1019 $(25,50 \mu \mathrm{g} / \mathrm{ml})$ for $3 \mathrm{~h}$ and $6 \mathrm{~h}$. The cells were incubated with $5 \mu \mathrm{M}$ of BODIPY $493 / 503$ for $5 \mathrm{~min}$ and washed with 1X-PBS ( $\mathrm{pH} 7.4$ ). The cells were imaged using the $63 \mathrm{X}$ oil-immersion objective lens of ZEISS ApoTome. 2 microscope provided with the appropriate filter. Similarly, the wild-type (BY4743) cells carrying pHL126 plasmid were grown till exponential phase $\left(\mathrm{OD}_{600}: 1-1.2\right)$ and left untreated (DMSO control) or treated with KP1019 (50, $75 \mu \mathrm{g} / \mathrm{ml})$. Then the localization of Sfp1 was analyzed after $1 \mathrm{~h}$ and $3 \mathrm{~h}$ of KP1019 treatment using $63 \mathrm{x}$ oil-immersion objective lens of ZEISS ApoTome. 2 microscope provided with the appropriate filter.

To test the effect of KP1019 on LDs in mammalian cells, HeLa cells were seeded in two-chambered slides (30,000 cells/well) using DMEM medium and left undisturbed for $24 \mathrm{~h}$. The cells were left untreated (DMSO control; final concentration $<0.5 \%$ ) or treated with KP1019 $(20,30 \mu \mathrm{M})$ for $36 \mathrm{~h}$. The cells were then stained with $5 \mu \mathrm{M}$ of BODIPY $493 / 503$ dye after $30 \mathrm{~min}$ fixation with $3.7 \%$ formaldehyde as indicated earlier [130]. The cells were imaged using the 40X objective lens of ZEISS ApoTome. 2 microscope provided with the appropriate filter. All the images were processed via ZEN-2012 (Blue edition) software. The quantitation of LDs both in yeast and HeLa cells was performed by counting the BODIPY 493/503 stained LDs in ApoTome images and represented as the number of LDs per cell.

\section{Measurement of Ruthenium ( $R u)$ content by Inductively Coupled Plasma Mass Spectrometry (ICP-MS)}

To assess the uptake of KP1019 by yeast cells, intracellular $\mathrm{Ru}$ levels were determined using ICP-MS 
as described previously [131]. A detailed description is provided in the supplementary information.

\section{Screening, validation, scoring, and functional analysis of $\mathrm{H3} / \mathrm{H} 4$ mutant library}

All the synthetic yeast histone $\mathrm{H} 3 / \mathrm{H} 4$ library mutants were pre-cultured in SC liquid medium (Uracil dropped) till the saturation in a 96-well plate. The cell density of cultures was normalized to an $\mathrm{OD}_{600}$ of 0.1 , and then replica spotted onto SC-agar tray plates that were supplemented without (DMSO control) or with $50 \mu \mathrm{g} / \mathrm{ml}$ of KP1019 (for sensitivity), $100 \mu \mathrm{g} / \mathrm{ml}$ of KP1019 (for resistance). The plates were incubated at $30^{\circ} \mathrm{C}$ and imaged after $48 \mathrm{~h}$. The growth fitness of mutants was compared to their respective wild-type cells spotted on the same plate and also to their corresponding fitness on the control (DMSO) plate. The mutants with decreased and increased fitness (in the presence of KP1019) compared to wild-type cells were assigned as KP1019 'sensitive' and 'resistant' respectively. For further confirmation, KP1019 sensitive and resistant mutants were validated by both the growth assays and growth curves as described above.

Each of KP1019 sensitive and resistant mutants was scored using the similar methodology described by Rizzardi et al. [132]. Briefly, those mutants exhibiting increased or decreased growth fitness (in the presence of KP1019) relative to wild-type controls were designated positive or negative scores respectively from 2 to 4 , with 2 being approximately a 10 -fold difference in growth and 4 being a 1000 -fold difference in growth.

For assessing the functional role of histone $\mathrm{H} 3$ / H4 residues whose mutants exhibited altered KP1019 tolerance, we extracted information about their position in the nucleosome, status of PTM, and associated phenotypes (along with scores) from the HistoneHits database [64]. The histone $\mathrm{H} 3 / \mathrm{H} 4$ residues whose mutants exhibited sensitivity to KP1019 were highlighted in the 3D yeast nucleosome structure (PDB ID: 1ID3) and visualized using PyMOL software.

\section{Human homologs of yeast KP1019 target genes and pathway analysis}

The target genes of KP1019 that were obtained here through yeast growth assays were used to identify the corresponding human homologs and their role in different human diseases using YeastMine tool [133]. Diseases annotations for human genes are provided according to the OMIM (Online Mendelian Inheritance in Man) database. The biological functions associated with the human homologs of yeast genes were analyzed using ToppCluster tool [134].

\section{Statistical analysis}

All the quantitative results are shown as Mean \pm SEM. The details about the number of independent experiments and experimental repeats are provided in the corresponding figure legends. Unless otherwise stated, statistical significance was assessed by performing Student's $t$-test (two-tailed; paired). $P<0.05$ considered as significant compared to control.

\section{Abbreviations}

KP, KP1019; PTMs, post-translational modifications; SC, synthetic complete medium; OD600, optical density measured at 600nm; DEGs, differentially expressed genes; DMSO, dimethyl sulfoxide; RT-PCR, reverse transcriptase- polymerase chain reaction; ICP-MS, inductively coupled plasma mass spectrometry; Ru, Ruthenium; GO, gene ontology; MTT, [3-(4,5-dimethylthiazol-2-yl)-2,5diphenyltetrazolium bromide]; CBBR, Coomassie brilliant blue R-250; TCA, trichloroacetic acid; MAPK, Mitogen-activated protein kinases; ROS, reactive oxygen species; RNR, ribonucleotide reductase; CWI, cell wall integrity; HOG, high osmolarity glycerol; ER, endoplasmic reticulum; LDs, lipid droplets; UPR, unfolded protein response; PE, Phosphatidylethanolamine; PC, phosphatidylcholine; FAs, fatty acids; BSO, buthionine sulfoximine; SERCA, sarcoplasmic/endoplasmic reticulum $\mathrm{Ca}^{2+}$-ATPase; $\mathrm{GSH}$, reduced glutathione; NAC, N-acetylcysteine; ETA, ethanolamine; MMS, methyl methanesulfonate; HU, hydroxyurea; TAG, triacylglycerols; SE, steryl esters; TLS, translesion synthesis; RAP, rapamycin; TOR, target of rapamycin; DTT, dithiothreitol; TM, tunicamycin.

\section{Author contributions}

UG and RST conceived, designed the study and analyzed the data. UG performed the screening and analysis of $\mathrm{H} 3 / \mathrm{H} 4$ library along with transcriptome analysis. $\mathrm{UG}$ and $\mathrm{SC}$ validated $\mathrm{H} 3 / \mathrm{H} 4$ mutants exhibiting the phenotype to KP1019. UG and SS performed all the experiments. UG wrote the manuscript as drafted by RST. All authors reviewed the results and approved the final version of the manuscript.

\section{ACKNOWLEDGMENTS AND FUNDING}

We thank Andrei Chabes, Joseph C Reese, Axel Mogk, and Sten Stymne for gifting us some of the yeast strains; Laran Jensen and David Shore for providing the plasmids used in this study. Also, we thank Robbie J. Loewith (University of Geneva) for providing AntiS758-P (Sch9 phosphorylation) antibody. Dr. Arundhuti Ghatak and Dr. Rajendar Nasani from IISER Bhopal were acknowledged for helping with the ICP-MS experiments 
and synthesis of KP1019 respectively. UG acknowledges MHRD, Government of India; SC and SS acknowledge CSIR, Government of India for providing the fellowship support. This work was supported by the funds from IISER Bhopal and DST Government of India to RST. All chromatin biology lab members were acknowledged for their helpful discussions.

\section{CONFLICTS OF INTEREST}

The authors declare no competing financial interests.

\section{REFERENCES}

1. Heffeter $P$, Jungwirth $U$, Jakupec $M$, Hartinger $C$, Galanski M, Elbling L, Micksche M, Keppler B, Berger W. Resistance against novel anticancer metal compounds: differences and similarities. Drug resistance updates. 2008; 11:1-16.

2. Hanahan D, Weinberg RA. The hallmarks of cancer. Cell. 2000; 100:57-70.

3. Hake SB, Xiao A, Allis CD. Linking the epigenetic 'language' of covalent histone modifications to cancer. British journal of cancer. 2004; 90:761-769.

4. Baylin SB, Jones PA. Epigenetic Determinants of Cancer. Cold Spring Harbor perspectives in biology. 2016; 8.

5. Missailidis S. Anticancer Therapeutics. Wiley: 2008.

6. Hartinger CG, Jakupec MA, Zorbas-Seifried S, Groessl M, Egger A, Berger W, Zorbas H, Dyson PJ, Keppler BK. KP1019, a new redox-active anticancer agent-preclinical development and results of a clinical phase I study in tumor patients. Chemistry \& biodiversity. 2008; 5:2140-2155.

7. Hartinger CG, Zorbas-Seifried S, Jakupec MA, Kynast B, Zorbas H, Keppler BK. From bench to bedsidepreclinical and early clinical development of the anticancer agent indazolium trans-[tetrachlorobis(1H-indazole) ruthenate (III)] (KP1019 or FFC14A). Journal of inorganic biochemistry. 2006; 100:891-904.

8. Heffeter P, Pongratz M, Steiner E, Chiba P, Jakupec MA, Elbling L, Marian B, Korner W, Sevelda F, Micksche M, Keppler BK, Berger W. Intrinsic and acquired forms of resistance against the anticancer ruthenium compound KP1019 [indazolium trans-[tetrachlorobis $(1 \mathrm{H}$-indazole $)$ ruthenate (III)] (FFC14A). The Journal of pharmacology and experimental therapeutics. 2005; 312:281-289.

9. Jones MR, Mu C, Wang MC, Webb MI, Walsby CJ, Storr T. Modulation of the Abeta peptide aggregation pathway by KP1019 limits Abeta-associated neurotoxicity. Metallomics. 2015; 7:129-135.

10. Trondl R, Heffeter P, Kowol CR, Jakupec MA, Berger W, Keppler BK. NKP-1339, the first ruthenium-based anticancer drug on the edge to clinical application. Chem Sci. 2014; 5:2925-2932.
11. Thompson DS, Weiss GJ, Jones SF, Burris HA, Ramanathan RK, Infante JR, Bendell JC, Ogden A, Von Hoff DD. NKP1339: Maximum tolerated dose defined for first-in-human GRP78 targeted agent. J Clin Oncol. 2012; 30.

12. Kuhn PS, Buchel GE, Jovanovic KK, Filipovic L, Radulovic S, Rapta P, Arion VB. Osmium (III) analogues of KP1019: electrochemical and chemical synthesis, spectroscopic characterization, X-ray crystallography, hydrolytic stability, and antiproliferative activity. Inorganic chemistry. 2014; 53:11130-11139.

13. Chang SW, Lewis AR, Prosser KE, Thompson JR, Gladkikh M, Bally MB, Warren JJ, Walsby CJ. CF3 Derivatives of the Anticancer Ru (III) Complexes KP1019, NKP-1339, and Their Imidazole and Pyridine Analogues Show Enhanced Lipophilicity, Albumin Interactions, and Cytotoxicity. Inorganic chemistry. 2016; 55:4850-4863.

14. Losantos BC, Pashkunova-Martic I, Kandler N, Keppler B. Studies of KP46 and KP1019 and the hydrolysis product of KP1019 in lipiodol emulsions: preparation and initial characterizations as potential theragnostic agents. Current drug delivery. 2016.

15. Heffeter P, Riabtseva A, Senkiv Y, Kowol CR, Korner W, Jungwith U, Mitina N, Keppler BK, Konstantinova T, Yanchuk I, Stoika R, Zaichenko A, Berger W. Nanoformulation improves activity of the (pre)clinical anticancer ruthenium complex KP1019. Journal of biomedical nanotechnology. 2014; 10:877-884.

16. Fischer B, Heffeter P, Kryeziu K, Gille L, Meier SM, Berger W, Kowol CR, Keppler BK. Poly (lactic acid) nanoparticles of the lead anticancer ruthenium compound KP1019 and its surfactant-mediated activation. Dalton Trans. 2014; 43:1096-1104.

17. Bijelic A, Theiner S, Keppler BK, Rompel A. X-ray Structure Analysis of Indazolium trans-[Tetrachlorobis(1Hindazole)ruthenate (III)] (KP1019) Bound to Human Serum Albumin Reveals Two Ruthenium Binding Sites and Provides Insights into the Drug Binding Mechanism. Journal of medicinal chemistry. 2016; 59:5894-5903.

18. Webb MI, Wu B, Jang T, Chard RA, Wong EWY, Wong MQ, Yapp DTT, Walsby CJ. Increasing the Bioavailability of Ru-III Anticancer Complexes through Hydrophobic Albumin Interactions. Chem-Eur J. 2013; 19:17031-17042.

19. Pongratz M, Schluga P, Jakupec MA, Arion VB, Hartinger CG, Allmaier G, Keppler BK. Transferrin binding and transferrin-mediated cellular uptake of the ruthenium coordination compound KP1019, studied by means of AAS, ESI-MS and CD spectroscopy. J Anal Atom Spectrom. 2004; 19:46-51.

20. Webb MI, Walsby CJ. EPR as a probe of the intracellular speciation of ruthenium (III) anticancer compounds. Metallomics. 2013; 5:1624-1633.

21. Blazevic A, Hummer AA, Heffeter P, Berger W, Filipits M, Cibin G, Keppler BK, Rompel A. Electronic State of Sodium trans-[Tetrachloridobis $(1 \mathrm{H}$-indazole)ruthenate 
(III)] (NKP-1339) in Tumor, Liver and Kidney Tissue of a SW480-bearing Mouse. Scientific reports. 2017; 7:40966.

22. Schluga P, Hartinger CG, Egger A, Reisner E, Galanski M, Jakupec MA, Keppler BK. Redox behavior of tumorinhibiting ruthenium (III) complexes and effects of physiological reductants on their binding to GMP. Dalton Trans. 2006; 1796-1802.

23. Kapitza S, Jakupec MA, Uhl M, Keppler BK, Marian B. The heterocyclic ruthenium (III) complex KP1019 (FFC14A) causes DNA damage and oxidative stress in colorectal tumor cells. Cancer letters. 2005; 226:115-121.

24. Singh V, Azad GK, Mandal P, Reddy MA, Tomar RS. Anticancer drug KP1019 modulates epigenetics and induces DNA damage response in Saccharomyces cerevisiae. FEBS letters. 2014; 588:1044-1052.

25. Malina J, Novakova O, Keppler BK, Alessio E, Brabec V. Biophysical analysis of natural, double-helical DNA modified by anticancer heterocyclic complexes of ruthenium (III) in cell-free media. Journal of biological inorganic chemistry. 2001; 6:435-445.

26. Stevens SK, Strehle AP, Miller RL, Gammons SH, Hoffman KJ, McCarty JT, Miller ME, Stultz LK, Hanson PK. The anticancer ruthenium complex KP1019 induces DNA damage, leading to cell cycle delay and cell death in Saccharomyces cerevisiae. Molecular pharmacology. 2013; 83:225-234

27. Bierle LA, Reich KL, Taylor BE, Blatt EB, Middleton SM, Burke SD, Stultz LK, Hanson PK, Partridge JF, Miller ME. DNA Damage Response Checkpoint Activation Drives KP1019 Dependent Pre-Anaphase Cell Cycle Delay in S. cerevisiae. PloS one. 2015; 10:e138085.

28. Singh V, Azad GK, Reddy MA, Baranwal S, Tomar RS. Anti-cancer drug KP1019 induces Hog1 phosphorylation and protein ubiquitylation in Saccharomyces cerevisiae. European journal of pharmacology. 2014; 736:77-85.

29. Botstein D, Fink GR. Yeast: an experimental organism for 21st Century biology. Genetics. 2011; 189:695-704.

30. Dos Santos SC, Teixeira MC, Cabrito TR, Sa-Correia I. Yeast toxicogenomics: genome-wide responses to chemical stresses with impact in environmental health, pharmacology, and biotechnology. Frontiers in genetics. 2012; 3:63.

31. Smith GS, Therrien B. Targeted and multifunctional arene ruthenium chemotherapeutics. Dalton Trans. 2011; 40:10793-10800.

32. Mewes HW, Frishman D, Guldener U, Mannhaupt G, Mayer K, Mokrejs M, Morgenstern B, Munsterkotter M, Rudd S, Weil B. MIPS: a database for genomes and protein sequences. Nucleic acids research. 2002; 30:31-34.

33. Rodriguez-Pena JM, Garcia R, Nombela C, Arroyo J. The high-osmolarity glycerol (HOG) and cell wall integrity (CWI) signalling pathways interplay: a yeast dialogue between MAPK routes. Yeast. 2010; 27:495-502.

34. Martin H, Rodriguez-Pachon JM, Ruiz C, Nombela C, Molina M. Regulatory mechanisms for modulation of signaling through the cell integrity Slt2-mediated pathway in Saccharomyces cerevisiae. J Biol Chem. 2000; 275:1511-1519.

35. Wada T, Penninger JM. Mitogen-activated protein kinases in apoptosis regulation. Oncogene. 2004; 23:2838-2849.

36. Azad GK, Singh V, Baranwal S, Thakare MJ, Tomar RS. The transcription factor Rap $1 p$ is required for tolerance to cell-wall perturbing agents and for cell-wall maintenance in Saccharomyces cerevisiae. FEBS letters. 2015; 589:59-67.

37. Sadafi FZ, Massai L, Bartolommei G, Moncelli MR, Messori L, Tadini-Buoninsegni F. Anticancer ruthenium (III) complex KP1019 interferes with ATP-dependent Ca2+ translocation by sarco-endoplasmic reticulum Ca2+-ATPase (SERCA). ChemMedChem. 2014; 9:1660-1664.

38. Yu D, Danku JM, Baxter I, Kim S, Vatamaniuk OK, Vitek O, Ouzzani M, Salt DE. High-resolution genome-wide scan of genes, gene-networks and cellular systems impacting the yeast ionome. BMC genomics. 2012; 13:623.

39. Bonilla M, Nastase KK, Cunningham KW. Essential role of calcineurin in response to endoplasmic reticulum stress. Embo Journal. 2002; 21:2343-2353.

40. Flocke LS, Trondl R, Jakupec MA, Keppler BK. Molecular mode of action of NKP-1339 - a clinically investigated ruthenium-based drug - involves ER- and ROS-related effects in colon carcinoma cell lines. Investigational new drugs. 2016; 34:261-268.

41. Gonzalez TN, Sidrauski C, Dorfler S, Walter P. Mechanism of non-spliceosomal mRNA splicing in the unfolded protein response pathway. The EMBO journal. 1999; 18:3119-3132.

42. Scrimale T, Didone L, de Mesy Bentley KL, Krysan DJ. The Unfolded Protein Response Is Induced by the Cell Wall Integrity Mitogen-activated Protein Kinase Signaling Cascade and Is Required for Cell Wall Integrity in Saccharomyces cerevisiae. Molecular biology of the cell. 2009; 20:164-175.

43. Nikawa JI, Yamashita S. Ire1 Encodes a Putative ProteinKinase Containing a Membrane-Spanning Domain and Is Required for Inositol Phototrophy in SaccharomycesCerevisiae. Mol Microbiol. 1992; 6:1441-1446.

44. Promlek T, Ishiwata-Kimata Y, Shido M, Sakuramoto M, Kohno K, Kimata Y. Membrane aberrancy and unfolded proteins activate the endoplasmic reticulum stress sensor Ire1 in different ways. Molecular biology of the cell. 2011; 22:3520-3532.

45. Madeira JB, Masuda CA, Maya-Monteiro CM, Matos GS, Montero-Lomeli M, Bozaquel-Morais BL. TORC1 inhibition induces lipid droplet replenishment in yeast. Molecular and cellular biology. 2015; 35:737-746.

46. Suresh HG, da Silveira Dos Santos AX, Kukulski W, Tyedmers J, Riezman H, Bukau B, Mogk A. Prolonged starvation drives reversible sequestration of lipid biosynthetic enzymes and organelle reorganization in Saccharomyces cerevisiae. Molecular biology of the cell. 2015; 26:1601-1615. 
47. Nielsen J. Systems biology of lipid metabolism: from yeast to human. FEBS letters. 2009; 583:3905-3913.

48. Natter K, Kohlwein SD. Yeast and cancer cells - common principles in lipid metabolism. Biochimica et biophysica acta. 2013 ; 1831:314-326

49. Sandager L, Gustavsson MH, Stahl U, Dahlqvist A, Wiberg E, Banas A, Lenman M, Ronne H, Stymne S. Storage lipid synthesis is non-essential in yeast. J Biol Chem. 2002; 277:6478-6482.

50. Kamisaka Y, Noda N, Tomita N, Kimura K, Kodaki T, Hosaka K. Identification of genes affecting lipid content using transposon mutagenesis in Saccharomyces cerevisiae. Bioscience, biotechnology, and biochemistry. 2006; 70:646-653

51. Gibellini F, Smith TK. The Kennedy pathway-De novo synthesis of phosphatidylethanolamine and phosphatidylcholine. IUBMB life. 2010; 62:414-428.

52. Powers T, Walter P. Regulation of ribosome biogenesis by the rapamycin-sensitive TOR-signaling pathway in Saccharomyces cerevisiae. Molecular biology of the cell. 1999; 10:987-1000.

53. Causton HC, Ren B, Koh SS, Harbison CT, Kanin E, Jennings EG, Lee TI, True HL, Lander ES, Young RA. Remodeling of yeast genome expression in response to environmental changes. Molecular biology of the cell. 2001; 12:323-337.

54. de Nadal E, Ammerer G, Posas F. Controlling gene expression in response to stress. Nature reviews Genetics. 2011; 12:833-845.

55. $\mathrm{Xu} \mathrm{Z,} \mathrm{Norris} \mathrm{D.} \mathrm{The} \mathrm{SFP1} \mathrm{gene} \mathrm{product} \mathrm{of} \mathrm{Saccharomyces}$ cerevisiae regulates $\mathrm{G} 2 / \mathrm{M}$ transitions during the mitotic cell cycle and DNA-damage response. Genetics. 1998; 150:1419-1428.

56. Marion RM, Regev A, Segal E, Barash Y, Koller D, Friedman N, O'Shea EK. Sfp1 is a stress- and nutrientsensitive regulator of ribosomal protein gene expression. Proceedings of the National Academy of Sciences of the United States of America. 2004; 101:14315-14322.

57. Lempiainen H, Uotila A, Urban J, Dohnal I, Ammerer G, Loewith R, Shore D. Sfp1 interaction with TORC1 and Mrs6 reveals feedback regulation on TOR signaling. Molecular cell. 2009; 33:704-716.

58. Urban J, Soulard A, Huber A, Lippman S, Mukhopadhyay D, Deloche O, Wanke V, Anrather D, Ammerer G, Riezman H, Broach JR, De Virgilio C, Hall MN, Loewith R. Sch9 is a major target of TORC1 in Saccharomyces cerevisiae. Molecular cell. 2007; 26:663-674.

59. Hsu PP, Kang SA, Rameseder J, Zhang Y, Ottina KA, Lim D, Peterson TR, Choi Y, Gray NS, Yaffe MB, Marto JA, Sabatini DM. The mTOR-regulated phosphoproteome reveals a mechanism of mTORC1-mediated inhibition of growth factor signaling. Science. 2011; 332:1317-1322.

60. Aitken JB, Antony S, Weekley CM, Lai B, Spiccia L, Harris HH. Distinct cellular fates for KP1019 and NAMI-A determined by X-ray fluorescence imaging of single cells. Metallomics. 2012; 4:1051-1056.

61. Li L, Kaplan J. Defects in the yeast high affinity iron transport system result in increased metal sensitivity because of the increased expression of transporters with a broad transition metal specificity. J Biol Chem. 1998; 273:22181-22187.

62. Kouzarides T. Chromatin modifications and their function Cell. 2007; 128:693-705.

63. Dai J, Hyland EM, Yuan DS, Huang H, Bader JS, Boeke JD. Probing nucleosome function: a highly versatile library of synthetic histone $\mathrm{H} 3$ and H4 mutants. Cell. 2008; 134:1066-1078.

64. Huang H, Maertens AM, Hyland EM, Dai J, Norris A, Boeke JD, Bader JS. HistoneHits: a database for histone mutations and their phenotypes. Genome research. 2009; 19:674-681.

65. Ruggero D, Pandolfi PP. Does the ribosome translate cancer? Nat Rev Cancer. 2003; 3:179-192.

66. Esteller M. Cancer epigenomics: DNA methylomes and histone-modification maps. Nature reviews Genetics. 2007; 8:286-298

67. Morgan MA, Shilatifard A. Chromatin signatures of cancer. Genes Dev. 2015; 29:238-249.

68. Gerhold DL, Jensen RV, Gullans SR. Better therapeutics through microarrays. Nat Genet. 2002; 32:547-552.

69. Jovanovic KK, Tanic M, Ivanovic I, Gligorijevic N, Dojcinovic BP, Radulovic S. Cell cycle, apoptosis, cellular uptake and whole-transcriptome microarray gene expression analysis of HeLa cells treated with a ruthenium (II)-arene complex with an isoquinoline-3-carboxylic acid ligand. Journal of inorganic biochemistry. 2016; 163:362-373.

70. Licona C, Spaety ME, Capuozzo A, Ali M, Santamaria R, Armant O, Delalande F, Van Dorsselaer A, Cianferani S, Spencer J, Pfeffer M, Mellitzer G, Gaiddon C. A ruthenium anticancer compound interacts with histones and impacts differently on epigenetic and death pathways compared to cisplatin. Oncotarget. 2017; 8:2568-2584. https://doi. org/10.18632/oncotarget.13711.

71. Jacinto E, Hall MN. Tor signalling in bugs, brain and brawn. Nature reviews Molecular cell biology. 2003; 4:117-126.

72. Gonzalez A, Hall MN. Nutrient sensing and TOR signaling in yeast and mammals. The EMBO journal. 2017; 36:397-408

73. Torres J, Di Como CJ, Herrero E, De La Torre-Ruiz MA. Regulation of the cell integrity pathway by rapamycinsensitive TOR function in budding yeast. J Biol Chem. 2002; 277:43495-43504.

74. Heffeter P, Atil B, Kryeziu K, Groza D, Koellensperger G, Korner W, Jungwirth U, Mohr T, Keppler BK, Berger W. The ruthenium compound KP1339 potentiates the anticancer activity of sorafenib in vitro and in vivo. Eur J Cancer. 2013; 49:3366-3375. 
75. Jiang BH, Liu LZ. Role of mTOR in anticancer drug resistance: perspectives for improved drug treatment. Drug resistance updates. 2008; 11:63-76.

76. Riaz H, Riaz T, Hussain SA. mTOR inhibitors: A novel class of anti-cancer agents. Infectious agents and cancer. 2012; 7:1.

77. Bilmen JG, Wootton LL, Michelangeli F. The inhibition of the sarcoplasmic/endoplasmic reticulum $\mathrm{Ca} 2+-\mathrm{ATPase}$ by macrocyclic lactones and cyclosporin A. The Biochemical journal. 2002; 366:255-263.

78. Devasahayam G, Burke DJ, Sturgill TW. Golgi manganese transport is required for rapamycin signaling in Saccharomyces cerevisiae. Genetics. 2007; 177:231-238.

79. Yatime L, Buch-Pedersen MJ, Musgaard M, Morth JP, Winther AML, Pedersen BP, Olesen C, Andersen JP, Vilsen B, Schiott B, Palmgren MG, Moller JV, Nissen P, Fedosova N. P-type ATPases as drug targets: Tools for medicine and science. Bba-Bioenergetics. 2009; 1787:207-220.

80. Bleeker NP, Cornea RL, Thomas DD, Xing C. A novel SERCA inhibitor demonstrates synergy with classic SERCA inhibitors and targets multidrug-resistant AML. Molecular pharmaceutics. 2013; 10:4358-4366.

81. Bleackley MR, Macgillivray RT. Transition metal homeostasis: from yeast to human disease. Biometals. 2011; 24:785-809.

82. Gramigni E, Tadini-Buoninsegni F, Bartolommei G, Santini G, Chelazzi G, Moncelli MR. Inhibitory effect of Pb2+ on the transport cycle of the $\mathrm{Na}+, \mathrm{K}+$-ATPase. Chemical research in toxicology. 2009; 22:1699-1704.

83. Vincent JB, Love S. The binding and transport of alternative metals by transferrin. Biochimica et biophysica acta. 2012; 1820:362-378.

84. Martin RB, Savory J, Brown S, Bertholf RL, Wills MR. Transferrin binding of $\mathrm{Al} 3+$ and $\mathrm{Fe} 3+$. Clinical chemistry. 1987; 33:405-407.

85. Farah IO, Trimble Q, Ndebele K, Mawson A. Significance of differential metal loads in normal versus cancerous cadaver tissues - biomed 2010. Biomedical sciences instrumentation. 2010; 46:404-409.

86. Warburg O. On the origin of cancer cells. Science. 1956; 123:309-314.

87. Shao W, Espenshade PJ. Expanding roles for SREBP in metabolism. Cell metabolism. 2012; 16:414-419.

88. Currie E, Schulze A, Zechner R, Walther TC, Farese RV Jr. Cellular fatty acid metabolism and cancer. Cell metabolism. 2013; 18:153-161.

89. Beloribi-Djefaflia S, Vasseur S, Guillaumond F. Lipid metabolic reprogramming in cancer cells. Oncogenesis. 2016; 5:e189.

90. Hapala I, Marza E, Ferreira T. Is fat so bad? Modulation of endoplasmic reticulum stress by lipid droplet formation. Biology of the cell. 2011; 103:271-285.
91. Hakumaki JM, Kauppinen RA. 1H NMR visible lipids in the life and death of cells. Trends in biochemical sciences. 2000; 25:357-362.

92. Murphy DJ, Vance J. Mechanisms of lipid-body formation. Trends in biochemical sciences. 1999; 24:109-115.

93. Boren J, Brindle KM. Apoptosis-induced mitochondrial dysfunction causes cytoplasmic lipid droplet formation. Cell death and differentiation. 2012; 19:1561-1570.

94. Walther TC, Farese RV Jr. Lipid droplets and cellular lipid metabolism. Annual review of biochemistry. 2012; 81:687-714.

95. Krahmer N, Farese RV Jr, Walther TC. Balancing the fat: lipid droplets and human disease. EMBO molecular medicine. 2013; 5:973-983.

96. Lee SJ, Zhang J, Choi AM, Kim HP. Mitochondrial dysfunction induces formation of lipid droplets as a generalized response to stress. Oxidative medicine and cellular longevity. 2013; 2013:327167.

97. Fei W, Wang H, Fu X, Bielby C, Yang H. Conditions of endoplasmic reticulum stress stimulate lipid droplet formation in Saccharomyces cerevisiae. The Biochemical journal. 2009; 424:61-67.

98. $\mathrm{Fu} \mathrm{S}$, Watkins SM, Hotamisligil GS. The role of endoplasmic reticulum in hepatic lipid homeostasis and stress signaling. Cell metabolism. 2012; 15:623-634.

99. Robciuc A, Hyotylainen T, Jauhiainen M, Holopainen JM. Hyperosmolarity-induced lipid droplet formation depends on ceramide production by neutral sphingomyelinase 2 . Journal of lipid research. 2012; 53:2286-2295.

100. Zirath H, Frenzel A, Oliynyk G, Segerstrom L, Westermark UK, Larsson K, Munksgaard Persson M, Hultenby K, Lehtio J, Einvik C, Pahlman S, Kogner P, Jakobsson PJ, Henriksson MA. MYC inhibition induces metabolic changes leading to accumulation of lipid droplets in tumor cells. Proceedings of the National Academy of Sciences of the United States of America. 2013; 110:10258-10263.

101. Fazolini NP, Cruz AL, Werneck MB, Viola JP, MayaMonteiro CM, Bozza PT. Leptin activation of mTOR pathway in intestinal epithelial cell triggers lipid droplet formation, cytokine production and increased cell proliferation. Cell Cycle. 2015; 14:2667-2676.

102. Welte MA. Expanding roles for lipid droplets. Current biology. 2015; 25:R470-481.

103. Nunn AD, Scopigno T, Pediconi N, Levrero M, Hagman H, Kiskis J, Enejder A. The histone deacetylase inhibiting drug Entinostat induces lipid accumulation in differentiated HepaRG cells. Scientific reports. 2016; 6:28025.

104. Poirier S, Samami S, Mamarbachi M, Demers A, Chang TY, Vance DE, Hatch GM, Mayer G. The epigenetic drug 5-azacytidine interferes with cholesterol and lipid metabolism. J Biol Chem. 2014; 289:18736-18751.

105. Tsui L, Chang SF, Huang HP, Fong TH, Wang IJ. YC-1 induces lipid droplet formation in RAW 264.7 macrophages. Journal of biomedical science. 2016; 23:2. 
106. Pan X, Wilson M, McConville C, Arvanitis TN, Griffin JL, Kauppinen RA, Peet AC. Increased unsaturation of lipids in cytoplasmic lipid droplets in DAOY cancer cells in response to cisplatin treatment. Metabolomics. 2013; 9:722-729.

107. Gansen A, Toth K, Schwarz N, Langowski J. Opposing roles of H3- and H4-acetylation in the regulation of nucleosome structure - a FRET study. Nucleic acids research. 2015; 43:1433-1443.

108. Iwasaki W, Miya Y, Horikoshi N, Osakabe A, Taguchi H, Tachiwana H, Shibata T, Kagawa W, Kurumizaka H. Contribution of histone N-terminal tails to the structure and stability of nucleosomes. FEBS open bio. 2013; 3:363-369.

109. Fraga MF, Ballestar E, Villar-Garea A, Boix-Chornet M, Espada J, Schotta G, Bonaldi T, Haydon C, Ropero S, Petrie K, Iyer NG, Perez-Rosado A, Calvo E, et al. Loss of acetylation at Lys 16 and trimethylation at Lys20 of histone H4 is a common hallmark of human cancer. Nat Genet. 2005; 37:391-400.

110. Kallappagoudar S, Yadav RK, Lowe BR, Partridge JF. Histone H3 mutations - a special role for H3.3 in tumorigenesis? Chromosoma. 2015; 124:177-189.

111. Chi P, Allis CD, Wang GG. Covalent histone modifications - miswritten, misinterpreted and mis-erased in human cancers. Nat Rev Cancer. 2010; 10:457-469.

112. Waldmann T, Schneider R. Targeting histone modifications - epigenetics in cancer. Current opinion in cell biology. 2013; 25:184-189.

113. Leroy G, Dimaggio PA, Chan EY, Zee BM, Blanco MA, Bryant B, Flaniken IZ, Liu S, Kang Y, Trojer P, Garcia BA. A quantitative atlas of histone modification signatures from human cancer cells. Epigenetics \& chromatin. 2013; 6:20.

114. Sharma SV, Lee DY, Li B, Quinlan MP, Takahashi F, Maheswaran S, McDermott U, Azizian N, Zou L, Fischbach MA, Wong KK, Brandstetter K, Wittner B, et al. A chromatin-mediated reversible drug-tolerant state in cancer cell subpopulations. Cell. 2010; 141:69-80.

115. Liao C, Hu B, Arno MJ, Panaretou B. Genomic screening in vivo reveals the role played by vacuolar $\mathrm{H}+$ ATPase and cytosolic acidification in sensitivity to DNA-damaging agents such as cisplatin. Molecular pharmacology. 2007; 71:416-425.

116. Mitra K, Carvunis AR, Ramesh SK, Ideker T. Integrative approaches for finding modular structure in biological networks. Nature reviews Genetics. 2013; 14:719-732.

117. Lipponer KG, Vogel E, Keppler BK. Synthesis, Characterization and Solution Chemistry of transIndazoliumtetrachlorobis (Indazole)Ruthenate (III), a New Anticancer Ruthenium Complex. IR, UV, NMR, HPLC Investigations and Antitumor Activity. Crystal Structures of trans-1-Methyl-Indazoliumtetrachlorobis-(1Methylindazole)Ruthenate (III) and its Hydrolysis Product trans-Monoaquatrichlorobis-(1-Methylindazole)-Ruthenate (III). Metal-based drugs. 1996; 3:243-260.
118. Golla U, Adhikary A, Mondal AK, Tomar RS, Konar S. Synthesis, structure, magnetic and biological activity studies of bis-hydrazone derived $\mathrm{Cu}$ (ii) and $\mathrm{Co}$ (ii) coordination compounds. Dalton Trans. 2016; 45:11849-11863.

119. Ito H, Fukuda Y, Murata K, Kimura A. Transformation of intact yeast cells treated with alkali cations. Journal of bacteriology. 1983; 153:163-168.

120. Azad GK, Singh V, Mandal P, Singh P, Golla U, Baranwal $\mathrm{S}$, Chauhan S, Tomar RS. Ebselen induces reactive oxygen species (ROS)-mediated cytotoxicity in Saccharomyces cerevisiae with inhibition of glutamate dehydrogenase being a target. FEBS open bio. 2014; 4:77-89.

121. Golla U, Bandi G, Tomar RS. Molecular cytotoxicity mechanisms of allyl alcohol (acrolein) in budding yeast. Chemical research in toxicology. 2015; 28:1246-1264.

122. Schmitt ME, Brown TA, Trumpower BL. A rapid and simple method for preparation of RNA from Saccharomyces cerevisiae. Nucleic acids research. 1990; 18:3091-3092.

123. Azad GK, Singh V, Golla U, Tomar RS. Depletion of cellular iron by curcumin leads to alteration in histone acetylation and degradation of Sml1p in Saccharomyces cerevisiae. PloS one. 2013; 8:e59003.

124. Golla U, Singh V, Azad GK, Singh P, Verma N, Mandal $\mathrm{P}$, Chauhan S, Tomar RS. Sen1p contributes to genomic integrity by regulating expression of ribonucleotide reductase 1 (RNR1) in Saccharomyces cerevisiae. PloS one. 2013; 8:e64798.

125. Golla U, Joseph D, Tomar RS. Combined Transcriptomics and Chemical-Genetics Reveal Molecular Mode of Action of Valproic acid, an Anticancer Molecule using Budding Yeast Model. Scientific reports. 2016; 6:35322.

126. Jensen AN, Chindaudomsate W, Thitiananpakorn K, Mongkolsuk S, Jensen LT. Improper protein trafficking contributes to artemisinin sensitivity in cells lacking the KDAC Rpd3p. FEBS letters. 2014; 588:4018-4025.

127. Miller JH. Experiments in molecular genetics. Cold Spring Harbor, NY: Cold Spring Harbor Laboratory; 1972.

128. Sariki SK, Sahu PK, Golla U, Singh V, Azad GK, Tomar RS. Sen1, the homolog of human Senataxin, is critical for cell survival through regulation of redox homeostasis, mitochondrial function, and the TOR pathway in Saccharomyces cerevisiae. Febs J. 2016; 283:4056-4083.

129. Hosiner D, Lempiainen H, Reiter W, Urban J, Loewith R, Ammerer G, Schweyen R, Shore D, Schuller C. Arsenic toxicity to Saccharomyces cerevisiae is a consequence of inhibition of the TORC1 kinase combined with a chronic stress response. Molecular biology of the cell. 2009; 20:1048-1057.

130. Cocchiaro JL, Kumar Y, Fischer ER, Hackstadt T, Valdivia RH. Cytoplasmic lipid droplets are translocated into the lumen of the Chlamydia trachomatis parasitophorous vacuole. Proceedings of the National Academy of Sciences of the United States of America. 2008; 105:9379-9384. 
131. Hostetter AA, Miranda ML, DeRose VJ, McFarlane Holman KL. Ru binding to RNA following treatment with the antimetastatic prodrug NAMI-A in Saccharomyces cerevisiae and in vitro. Journal of biological inorganic chemistry. 2011; 16:1177-1185.

132. Rizzardi LF, Dorn ES, Strahl BD, Cook JG. DNA replication origin function is promoted by $\mathrm{H} 3 \mathrm{~K} 4$ di-methylation in Saccharomyces cerevisiae. Genetics. 2012; 192:371-384.

133. Balakrishnan R, Park J, Karra K, Hitz BC, Binkley G, Hong EL, Sullivan J, Micklem G, Cherry JM. YeastMine - an integrated data warehouse for Saccharomyces cerevisiae data as a multipurpose tool-kit.
Database: the journal of biological databases and curation. 2012; 2012:bar062.

134. Kaimal V, Bardes EE, Tabar SC, Jegga AG, Aronow BJ. ToppCluster: a multiple gene list feature analyzer for comparative enrichment clustering and network-based dissection of biological systems. Nucleic acids research. 2010; 38:W96-102. 